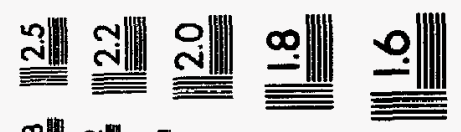

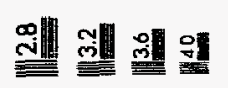

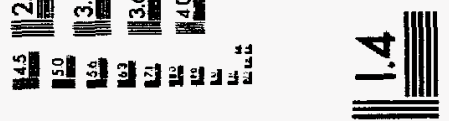

$$
\begin{aligned}
& \text { 에||||데 }
\end{aligned}
$$





\title{
NUCLEAR REACTION ANALYSIS OF HYDROGEN IN SSC BEAM PIPE MATERIALS
}

\author{
M. W. Ruckman and Myron Strongin \\ Physics Department \\ Brookhaven National Laboratory, Upton, New York 11973
}

W. A. Lanford
Department of Physics
State University of New York at Albany, Albany, New York, 12222

\section{DISCLAIMER}

This report was prepared as an account of work sponsored by an agency of the United States Government. Neither the United States Government nor any agency thereof, nor any of their employees, makes any warranty, express or implied, or assumes any legal liability or responsibility for the accuracy, completeness, or usefulness of any information, apparatus, product, or process disclosed, or represents that its use would not infringe privately owned rights. Reference herein to any specific commercial product, process, or service by trade name, trademark, manufacturer, or otherwise does not necessarily constitute or imply its endorsement, recommendation, or favoring by the United States Government or any agency thereof. The views and opinions of authors expressed herein do not necessarily state or reflect those of the United States Government or any agency thereof.

\section{MASTER}


NUCLEAR REACTION ANALYSIS OF HYDROGEN IN SSC BEAM PIPE MATERIALS

\author{
M. W. Ruckman and Myron Strongin \\ Physics Department \\ Brookhaven National Laboratory, Upton, New York 11973
}

W. A. Lanford

Department of Physics

State University of New York at Albany, Albany, New York, 12222

\title{
I. Introduction
}

The $20 \mathrm{TeV}$ proton beam circulating in the Superconducting SuperCollider (SSC) would have emitted enough synchrotron radiation that the photon-stimulated desorption of gas molecules (principally hydrogen ) would have had a significant impact on the vacuum pressure during SSC operation. [1] Photon-stimulated desorption could also be a problem for other TeV-scale colliders like the proposed Large Hadron Collider (LHC) at CERN. Photodesorption experiments [2] on cold ( LHe temperature) beam pipe sections show that significant amounts of molecular hydrogen accumulate on the cold pipe wall with increasing photon irradiation and reach a point where a "monolayer" forms when the exposure reaches $10^{21}-10^{22}$ photons $/ \mathrm{m}$. At this point the equilibrium vapor pressure rapidly increases and the beam pipe vacuum deteriorates. Since the proposed SSC would have delivered $10^{21}-10^{22}$ photons $/ \mathrm{m}$ to the beam pipe surface in 8.6 days during baseline operations [2], the estimated photodesorption levels could have imposed an unwanted upper bound on Collider operation.

To control the photodesorption of molecular hydrogen, it is advantageous to reduce the amount of hydrogen in candidate SSC beam pipe materials and identify those procedures that: (1) lead to contamination of the beam pipe surface or materials, (2) would reduce the amount 
of hydrogen on the surface or in the bulk and (3) could be used for in-situ cleaning during Collider assembly or during Collider maintenance. Nuclear Reaction Analysis (NRA) can be used to quantitatively measure the amount of hydrogen on the surface or within half a micron of the surface. The present report discusses data that has been obtained for candidate SSC beam pipe materials ( Nitronix 40 Stainless Steel, Nitronix 40 SS coated with electrodeposited copper (Silvex process)), oxygen-free high conductivity copper (Hitachi 101 OFHC) and several miscellaneous samples. The work demonstrates the potential of the technique for characterizing the hydrogen concentration of accelerator beam pipe materials, for assisting in the development of better vacuum system materials for $\mathrm{TeV}$-scale accelerators, and for the development of better beam pipe construction or maintenance procedures for future accelerator projects.

\section{The Experiment}

The Nuclear Reaction Analysis (NRA) was done at the SUNY-Albany Accelerator Laboratory whose dynamitron accelerator produced the $6.36-7.4 \mathrm{MeV}{ }^{15} \mathrm{~N}$ beam used to probe for hydrogen. The basic idea behind the experiment is that the ${ }^{15} \mathrm{~N}$ ions bombarding the sample will undergo nuclear reactions with the hydrogen in the sample and emit $\gamma$-rays in an amount proportional to the hydrogen concentration. The ${ }^{15} \mathrm{~N}$ reaction method is illustrated in Figure 1 and key physical parameters are summarized in Table I taken from ref. (3). The specific nuclear reaction is :

$$
{ }^{15} \mathrm{~N}+\mathrm{H} \rightarrow{ }^{16} \mathrm{O} \rightarrow{ }^{12} \mathrm{C}+{ }^{4} \mathrm{He}+\gamma
$$

As Figure 1 illustrates, the beam is incident on the sample and the yield of the characteristic $\gamma$ - 
ray $(4.43 \mathrm{MeV})$ is measured. The ${ }^{15} \mathrm{~N}+\mathrm{H}$ reaction is a resonant reaction and the reaction cross-section (shown in Fig. 2) is more than four orders of magnitude larger on resonance than off resonance. This large enhancement of the reaction cross section at the resonance energy, $\mathrm{E}_{\text {res }},(6.4 \mathrm{MeV})$ makes the ${ }^{15} \mathrm{~N}+\mathrm{H}$ reaction particularly effective for concentration depth profiling. For example, if the sample is bombarded by ${ }^{15} \mathrm{~N}$ ions at the resonant energy, the ions will react with the surface hydrogen atoms and the $\gamma$-ray yield will be proportional to the surface hydrogen concentration. If a sample is bombarded with ${ }^{15} \mathrm{~N}$ ions with an energy above the resonance energy, the ${ }^{15} \mathrm{~N}$ ions will lose energy penetrating the sample and then the $\gamma$-ray energy will be proportional to the hydrogen concentration at that depth.

The apparatus used for the NRA measurements is thoroughly described in ref. 4 which reviews the use of the NRA technique for hydrogen analysis. Figure 3 shows a schematic of the chamber used for this analysis. The chamber was pumped using a diffusion pump and forepump and reached a vacuum in the $10^{-6}$ Torr range during analysis. Pump down times were on the order of ten minutes. The samples were pieces of beam pipe (33 $\mathrm{mm}$ in diameter) cut in half along the long axis. Most of the pieces were cleaned by the NSLS Vacuum Group using the same procedures employed on samples used for photodesorption testing. After cleaning, the samples were wrapped in lint free tissue and handled using standard UHV procedures. A subset of the samples were not cleaned but were handled using the same procedures as the cleaned samples. The samples were clipped into the rotatable sample wheel shown in Fig. 3 for analysis.

A typical run consisted of the following: (1) Before irradiating the samples, the ${ }^{15} \mathrm{~N}$ beam was positioned on a fluorescent target and the beam focused to a small spot. The beam was then 
rastered over a square $6 \times 6$ millimeters wide. (2) After placing a Bismuth Germanate (BGO) scintillation detector in place, the beam was shuttered and the sample moved into position. (3) The sample was irradiated with a monoenergetic ${ }^{15} \mathrm{~N}$ ion beam and the $\gamma$-ray yield detected. The ${ }^{15} \mathrm{~N}$ dose irradiation was measured by integrating the current carried to the target by the ${ }^{15} \mathrm{~N}$ ions. The raw data ( $\gamma$-ray yield vs beam energy) is shown in Figure 4. The conversion of the data to hydrogen concentration versus depth is straight forward. Because at this energy range, the energy loss rate, $d E / d x$, of the ${ }^{15} \mathrm{~N}$ ions is constant with energy to a few percent, the analysis depth is given by:

$$
x=\frac{\left(E-E_{r e s}\right)}{\frac{d E}{d x}}
$$

The $\gamma$-ray yield is computed from the energy-integrated Breit-Wigner formula for a resonant cross section, (i.e. proportional to $(\pi / 2) \sigma_{0} \Gamma$ ), where $\sigma_{0}$ is the cross section at the resonant energy, and $\Gamma$ is the width of the resonance). The $\gamma$-ray yield is also proportional to the energy loss $(\mathrm{dE} / \mathrm{dx})$ of the incident ions because $\gamma$-ray yield is related to the amount of hydrogen within the resonance detection window and this is proportional to the thickness of the resonance detection window. This thickness is inversely proportional to $\mathrm{dE} / \mathrm{dx}$. For this experiment, the hydrogen concentration $\rho_{\mathrm{H}}$ was computed using the following expression:

$$
\rho_{H}=\left(0.45 \times 10^{19}\right) \frac{d E}{d x} Y
$$

where $\rho_{\mathrm{H}}$ is the density of hydrogen in atoms $/ \mathrm{cm}^{3}, \mathrm{dE} / \mathrm{dx}$ is the energy loss and $\mathrm{Y}$ is the $\gamma$-ray 
yield for a $2 \mu$ Coulomb ${ }^{15} \mathrm{~N}$ ion dose. $\gamma$ The prefactor $0.45 \times 10^{19}$ depends on the reaction cross section, detector efficiency etc. but is sample independent. For the experimental set-up used, this prefactor was determined using a variety of samples with known hydrogen concentrations.

An uncertainty in the experimental results is imposed by the loss of hydrogen from the samples during the experiment (out gassing) or its uptake from the residual gases in the vacuum chamber. The loss of hydrogen can also be stimulated by the ${ }^{15} \mathrm{~N}$ ions. We believe the amount of (beam off) out gassing and adsorption of hydrogen from the vacuum are negligible because measurements on adjacent spots on a single sample scanned at the beginning of sample analysis and about a half hour later showed no difference in the amount of surface hydrogen. The problem of hydrogen loss during ${ }^{15} \mathrm{~N}$ irradiation can be evaluated by examining the variation of measured hydrogen concentration as a function of dose. Figure 5 shows the loss of hydrogen during $0.2 \mu \mathrm{C}$ irradiation steps giving a cumulative dose ranging from 0.2 to $8 \mu \mathrm{C}$. The $\gamma$-ray signal decreases with increasing ${ }^{15} \mathrm{~N}$ dose by a factor of 2 over the range of doses studied and much of the hydrogen loss occurs within the first $2 \mu \mathrm{C}$ dose of ${ }^{15} \mathrm{~N}$ ions. Using the signal vs dose plot, it can be inferred that the hydrogen loss is small provided the ${ }^{15} \mathrm{~N}$ dose is limited to a few tenths of a $\mu \mathrm{C}$. For the purposes of this experiment the ${ }^{15} \mathrm{~N}$ flux can be estimated from the area irradiated and the fact that the nitrogen ions have a charge of +2 . The ${ }^{15} \mathrm{~N}$ dose is $8.67 \times 10^{12}{ }^{15} \mathrm{~N} / \mathrm{cm}^{3}$ per $\mu \mathrm{C}$ of beam.

\section{Results and Analysis}

The experimental data is summarized in Table III which gives the measured surface and 
bulk hydrogen atom densities for Silvex electrodeposited copper, Hitachi 101 OFHC copper, Nitronix 40 Stainless Steel at a silicon wafer used as a standard to measure the $\gamma$-ray background. Hydrogen concentration profiles for all the materials summarized in Table III and a few miscellaneous samples are plotted and shown as Figures 6-19. The hydrogen densities deduced by NRA are surprisingly similar for all of the SSC supplied materials. The plots of hydrogen show that each SSC sample has a surface peak of hydrogen on the order of 2-5 $\times 10^{16}$ $\mathrm{H} / \mathrm{cm}^{2}$. In general the surface hydrogen density exceeds that of the bulk by about two orders of magnitude. The Silvex copper samples showed a bulk hydrogen density of $1.5 \times 10^{21} \mathrm{H} / \mathrm{cm}^{3}$ for the sample cleaned by the NSLS vacuum group and $1.3 \times 10^{21} \mathrm{H} / \mathrm{cm}^{3}$ for the control sample not cleaned and scanned as received from SSCL. The hydrogen content of the bulk Hitachi 101 OFHC copper is also very high ranging from $6.1 \times 10^{20} \mathrm{H} / \mathrm{cm}^{3}$ for the cleaned sample to $9.1 \mathrm{x}$ $10^{20} \mathrm{H} / \mathrm{cm}^{3}$ for the control sample. It is surprising that the OFHC sample has so much hydrogen given the extremely low solubility of hydrogen in bulk copper. It is not as surprising that the Silvex copper contains on the order or $0.01-0.10$ at $\%$ hydrogen since the material was deposited electrochemically. As expected the Nitronix 40 stainless steel had the largest bulk concentration of hydrogen. Interestingly, the surface hydrogen concentration of the stainless steel is comparable to the copper samples.

The area density of the surface hydrogen was evaluated by integrating the area of a fitted Gaussian peak (see Fig. 8 ) or an asymmetric double sigmoid peak where the surface hydrogen peak showed a clear tailing off into the bulk. The surface areal densities range from: 2.3-2.6 $\times 10^{16} \mathrm{H} / \mathrm{cm}^{2}$ for the cleaned copper surfaces, 3.2-4.7 $\times 10^{16} \mathrm{H} / \mathrm{cm}^{2}$ for the uncleaned control samples, and $4.5 \times 10^{16} \mathrm{H} / \mathrm{cm}^{2}$ for the Nitronix 40 sample. A natural question to pose is whether 
the surface hydrogen amounts measured using NRA are compari. evolved from these surfaces during photodesorption experiments. materials has been done for both warm [5] and cold SSC beam ? comparison, results from a warm tube experiment on a clean $b$ : copper tube will be used. The photodesorption run exposed the $c$ photons per meter at the U10b facility at Brookhaven. During th hydrogen evolved was 1.7 Torr-liters. Converting this to the total liberated by the synchrotron radiation gives $6.0 \times 10^{19}$ total $\mathrm{F}$ beam pipe or $5.8 \times 10^{16} \mathrm{H}_{2} / \mathrm{cm}^{2}$. The comparable value from the $\mathrm{H}_{2} / \mathrm{cm}^{2}$. The NRA estimate of the surface hydrogen is within a warm tube photodesorption of hydrogen. When compared to the $8.0 \times 10^{17} \mathrm{H}_{2}$ molecules were thermally desorbed from a cold $\mathrm{tt}$ $x 10^{21}$ photons. The NRA value is clearly larger than the $7.7 \%$ experiment. It should also be observed that the amount of surf: needed to saturate the surface $\left(3 \times 10^{15} \mathrm{H}_{2} / \mathrm{cm}^{2}\right)$ by a factor of

Comparison of the NRA data with previous photodesorp the surface hydrogen peak believed to be connected to a hydrı)g $100 \AA$ thick contains enough hydrogen to account for much of the into the SSC vacuum. Whether it accounts for most of the hycirc results are consistent with observations drawn during warm tube that the amount of hydrogen photodesorption is somewhat sam materials. The NRA analysis suggests all unbaked samples have $a$ he amounts of hydrogen iesorption of comparable ?]. For the purposes of ked Silvex electroplated coated tube to $1.0 \times 10^{23}$ the amount of molecular r of hydrogen molecules sules for the one meter xperiment is $1.15 \times 10^{15}$ of 5-6 of the measured :be experiment in which $2 r$ the application of 1.9 $\mathrm{I}_{2} / \mathrm{cm}^{2}$ measured in that irogen also exceeds that xperiments suggests that in surface layer less than nted hydrogen that enters $s$ an open question. The :odesorption experiments independent for unbaked iar hydrogen-rich surface 
layer that is acquired either during the cleaning process or by exposure to atmosphere. Hence, it is logical to assume that the photodesorption will be same because the surfaces have a common characteristic.

The NRA analysis of the Si wafer provides an important check on the reliability of the surface and bulk hydrogen density measurements. The Si has an insignificant bulk hydrogen concentration and the $\gamma$-ray signal for bulk $\mathrm{Si}$ was two orders of magnitude smaller for the $\mathrm{Si}$ than the best copper sample. The surface hydrogen peak was smaller for Si than the copper samples. Hydrogen contamination of copper surfaces was also studied in conjunction with efforts to develop a cold neutron "bottle" [6]. For an unbaked $\mathrm{Cu}$ bottle showing high neutron capture losses, the peak surface hydrogen area density was $2 \times 10^{16} \mathrm{H} / \mathrm{cm}^{2}$. In the case of the copper studied for the neutron bottle, the hydrogen containing layer was estimated to be $30 \AA$ thick. The surface hydrogen values measured for Silvex electrodeposited copper and Hitachi 101 OFHC copper are comparable to those measured for similar copper samples over fifteen years ago [6].

NRA analysis was also done on some copper samples electroplated in a heavy water solution, a gold film and a nickel film (Figs. 14-19). All the samples showed a hydrogen-rich surface layer and the copper film made in heavy water had the same bulk hydrogen concentration as the Silvex copper sample. The gold film had nearly two orders of magnitude more bulk hydrogen than the copper samples and even more hydrogen than the Nitronix 40 stainless steel. The Ni film resembled the Nitronix 40 sample in the amount of hydrogen. Clearly, the plating procedures have a profound impact on the amount of hydrogen incorporated in the samples. The amount of hydrogen uptake during electroplating is not clear. The idea behind using a heavy 
water solvent was to substitute deuterium for hydrogen during electroplating and hope that the physical properties of deuterium would minimize its escape into the vacuum. The $\mathrm{N}^{15}$-based NRA can also detect deuterium, but a careful examination of the $\gamma$-ray spectrum showed that the samples contained little or no deuterium. This casts doubt on the incorporation of hydrogen and certainly deuterium from the water used in electrodeposition. The culprit might be the additives used during various electrodeposition process to control vanous thin film properties.

Figures 20 \& 21 show plots of the surface hydrogen peaks for cleaned and not cleaned Silvex electroplated copper and Hitachi 101 OFHC copper. The NRA technique can discriminate between the cleaned and not cleaned surfaces and show: (1) the amount of surface hydrogen is reduced upon cleaning and (2) the thickness of the hydrogen-rich surface layer is reduced by cleaning.

\section{Summary}

The NRA experiment detailed in this report provides useful new data concerning the amount of hydrogen in candidate SSC beam pipe materials. All of the samples studied have hydrogen-rich surface layers that contain on the order of $2-5 \times 10^{16} \mathrm{H} / \mathrm{cm}^{2}$. This is comparable in magnitude to the amount of hydrogen evolved during warm tube photodesorption experiments where $10^{22}-10^{23}$ photons $/ \mathrm{m}\left(10^{18}-10^{19}\right.$ photons $\left./ \mathrm{cm}^{2}\right)$ are applied to the surfaces of beam pipe materials. This suggests that the surface layer contains a significant fraction, if not, most of une hydrogen being converted to molecular hydrogen in the beam pipe. Hydrogen diffusion from the bulk may also be a problem and a superficial assessment of the results shows that the bulk 
copper hydrogen densities are surprisingly large (i.e., on the order of $0.01-0.1$ at $\% \mathrm{H}$ ).

\section{Acknowledgements}

Partial support was provided by the U.S. Dept. of Energy, Division of Materials Sciences under Contract No. DE-ACO2-76CH00016. 


\section{REFERENCES}

1. V. V. Anashin, O. Malyshev, V. N. Osipov, I. L. Maslennikov and W. C. Tumer, "Investigation of Synchrotron Radiation-Induced Photodesorption in Cryosorbing Quasi-Closed Geometry", SSCL-Preprint-517 (submitted to Physical Review Letters).

2. V. Anashin, A. Evstigneev, O. Malyshev, V. Osipov, I Maslennikov and W. Tumer, "Summary of Recent Photodesorption Experiments at VEPP2M", SSCL Report No. SSCL-N825, (June, 1993).

3. F. Xiong, F. Rauch, C. Shi, Z. Zhou, R. P. Lvi and T. A. Tombrello, Nuc. Instr. and Meth. B 27, 432, (1987).

4. W. A. Lanford, Nuc. Instr. and Meth. B 66, 65, (1992).

5. C. Foerester, C. Lanni, I Maslennikov and W. Turner, "Photon Desorption Measurements of Copper and Copper Platted Beam Tubes for the SSCL $20 \mathrm{TeV}$ Proton Collider", (to be published in J. Vac. Sci. Technol.).

6. W. A. Lanford and R. Golub, Phys. Rev. Lett, 39, 1509 (1977). 
Table I

Nuclear Reaction Cross Section Characteristics ${ }^{\mathrm{a}}$

\begin{tabular}{||l|c|c|}
\hline \multicolumn{1}{|c|}{ Reaction } & ${ }^{15} \mathbf{N}+\mathbf{H}$ & ${ }^{15} \mathbf{H}+\mathbf{H}$ \\
\hline Resonance energy $[\mathrm{MeV}]$ & 6.385 & 13.35 \\
\hline $\begin{array}{l}\text { Cross section }\left(\sigma_{0}\right) \\
\text { at resonance }[\mathrm{mb}]\end{array}$ & 1650 & 1050 \\
\hline Resonance width $(\Gamma)[\mathrm{keV}]$ & 1.8 & 25.4 \\
\hline$\sigma_{0} \Gamma[\mathrm{mb} \cdot \mathrm{keV}]$ & 2970 & 26700 \\
\hline Relative yield & 1.000 & 9.0 \\
\hline $\mathrm{dE} / \mathrm{d} \times$ in Si $[\mathrm{MeV} / \mu \mathrm{m}]$ & 1.45 & 1.35 \\
\hline$(\Gamma) / \mathrm{dE} / \mathrm{d} \times[\mu \mathrm{m}]$ & 0.0012 & 0.0188 \\
\hline $\begin{array}{l}\text { Energy of next resonance } \\
{[\mathrm{MeV})}\end{array}$ & 13.35 & 18.0 \\
\hline Gamma-ray energy $[\mathrm{MeV}]$ & 4.43 & 4.43 \\
\hline
\end{tabular}

a From Xiong et al. (Ref.[3]). 
Table II

Metal Matrix Parameters (Density and $\mathrm{N}^{15}$ Energy Loss )

\begin{tabular}{||c|c|c|c|c||}
\hline \hline Element $\rightarrow$ & $\mathrm{Cu}$ & $\mathrm{Fe}$ & $\mathrm{Au}$ & $\mathrm{Si}$ \\
\hline $\mathrm{Z}$ & 29 & 26 & 79 & 14 \\
\hline$\rho\left(\mathrm{g} / \mathrm{cm}^{3}\right)$ & 8.96 & 7.86 & 19.3 & 2.33 \\
\hline $\begin{array}{l}\mathrm{n}\left(10^{22} \text { atoms } /\right. \\
\left.\mathrm{cm}^{3}\right)\end{array}$ & 8.46 & 8.06 & 5.90 & 5.0 \\
\hline $\begin{array}{l}\mathrm{dE} / \mathrm{dx}(\mathrm{MeV} / \\
\mathrm{mg} \mathrm{cm})\end{array}$ & 3.78 & 4.53 & 2.02 & 6.05 \\
\hline $\begin{array}{l}\mathrm{dE} / \mathrm{dx} \\
(\mathrm{MeV} / \mu)\end{array}$ & 3.39 & 3.56 & 3.89 & 1.41 \\
\hline
\end{tabular}




\section{Table III}

Hydrogen Densities in SSC Beam Pipe Materials

\begin{tabular}{||c|c|c|c|}
\hline Material & $\begin{array}{c}\rho \text { (surface peak) } \\
\text { H atoms } / \mathrm{cm}^{3}\end{array}$ & $\begin{array}{c}\rho \text { (bulk) } \\
\mathbf{H} \text { atoms } / \mathrm{cm}^{3}\end{array}$ & $\begin{array}{c}\text { Sur ce } \rho \\
\text { H atoms } / \mathrm{cm}^{2}\end{array}$ \\
\hline Silvex (cleaned) & $4.8 \times 10^{22}$ & $1.5 \times 10^{21}$ & $2.3 \times 10^{16}$ \\
\hline Silvex (not cleaned) & $4.5 \times 10^{22}$ & $1.3 \times 10^{21}$ & $3.2 \times 10^{16}$ \\
\hline $\begin{array}{c}\text { Hitachi 101 } \\
\text { (cleaned) }\end{array}$ & $3.9 \times 10^{22}$ & $6.1 \times 10^{20}$ & $2.6 \times 10^{16}$ \\
\hline $\begin{array}{c}\text { Hitachi 101 } \\
\text { (not cleaned) }\end{array}$ & $4.9 \times 10^{22}$ & $9.1 \times 10^{20}$ & $4.7 \times 10^{16}$ \\
\hline $\begin{array}{c}\text { Nitronix 40 } \\
\text { (not cleaned) }\end{array}$ & $5.9 \times 10^{22}$ & $2.8 \times 10^{21}$ & $4.5 \times 10^{16}$ \\
\hline Silicon Wafer & $9.0 \times 10^{21}$ & $<10^{18}$ & $9.3 \times 10^{15}$ \\
\hline
\end{tabular}




\section{I ว.นกริ!}

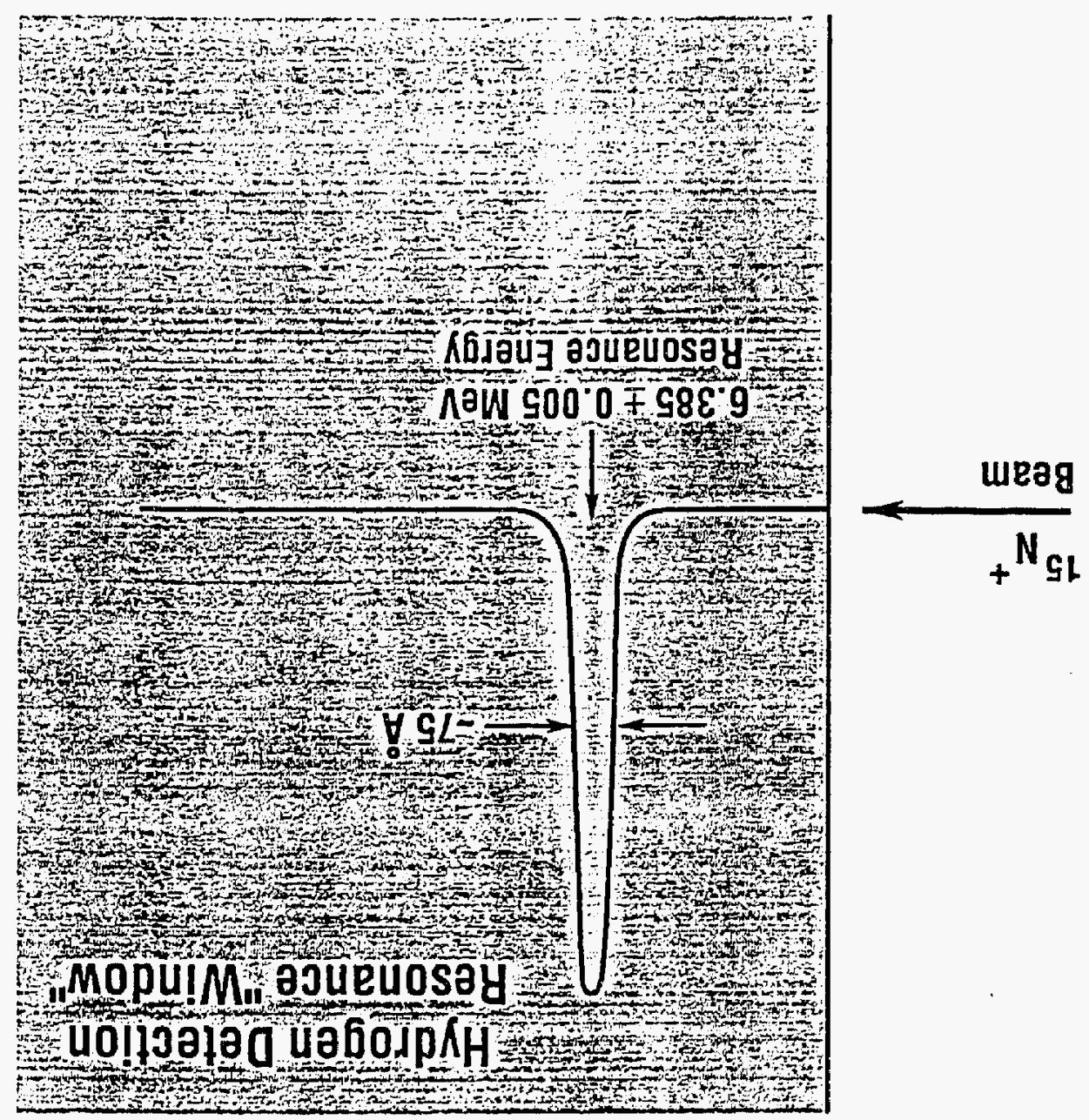




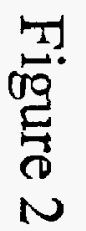

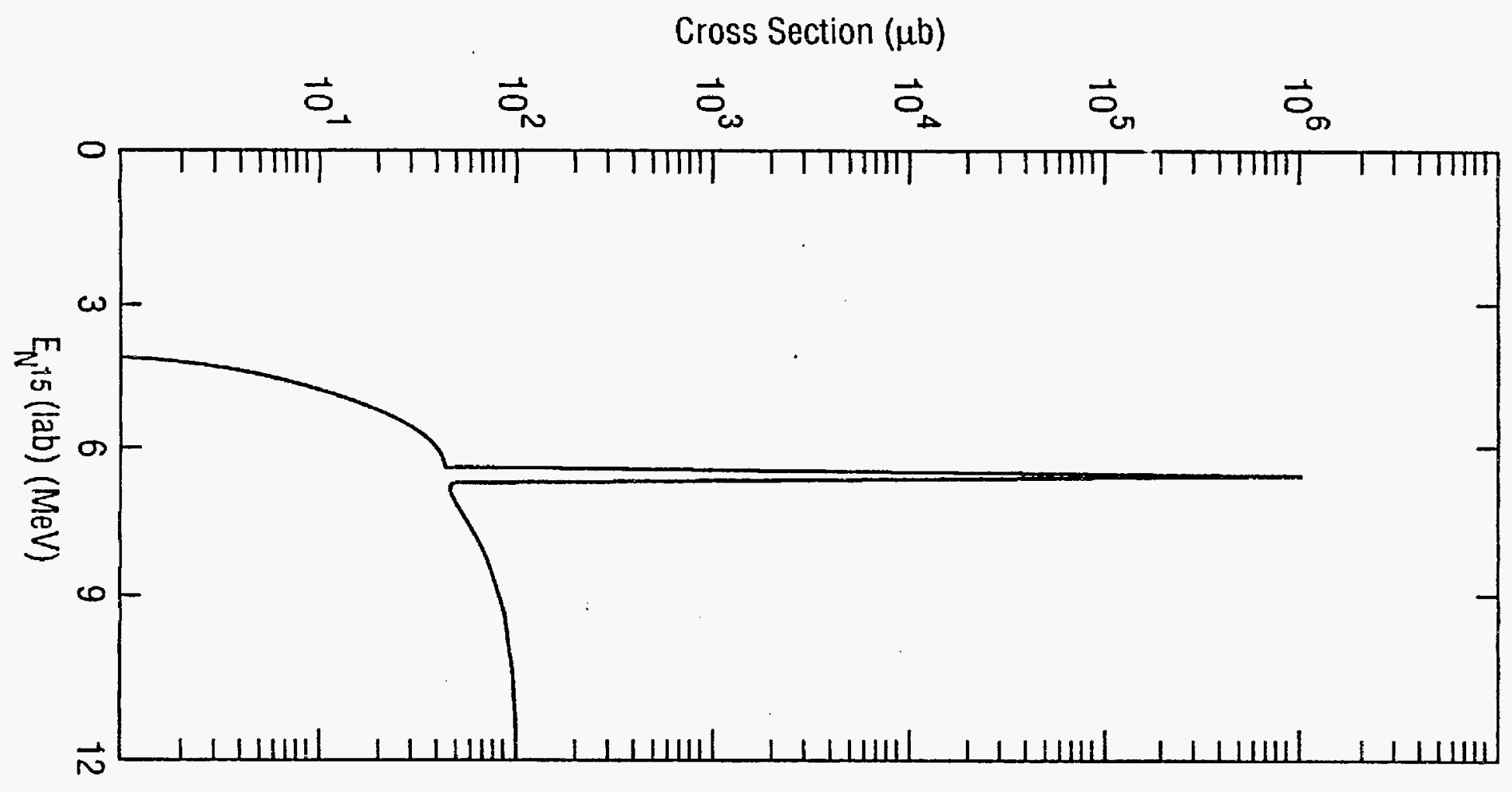




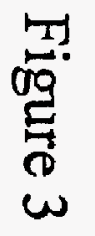

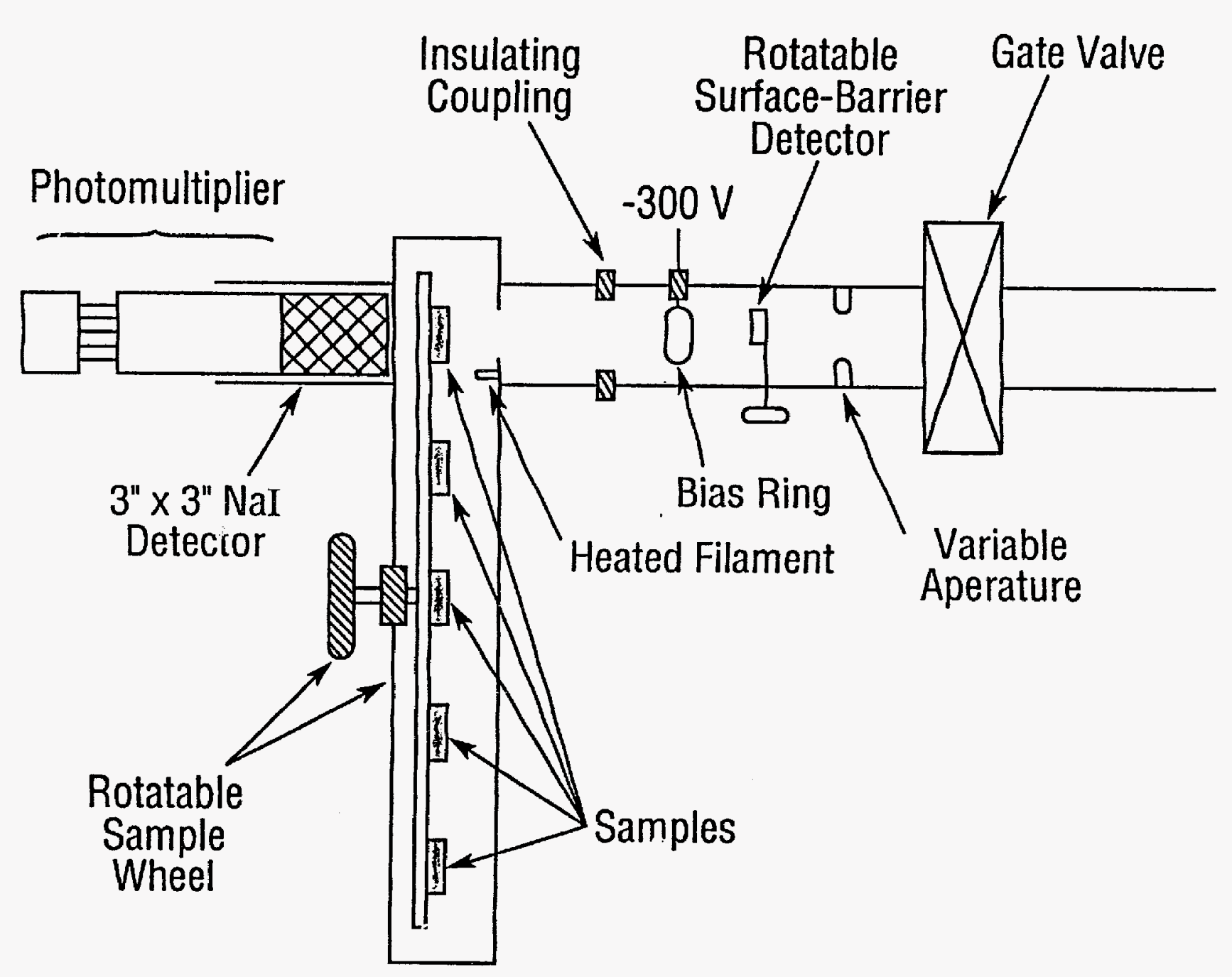




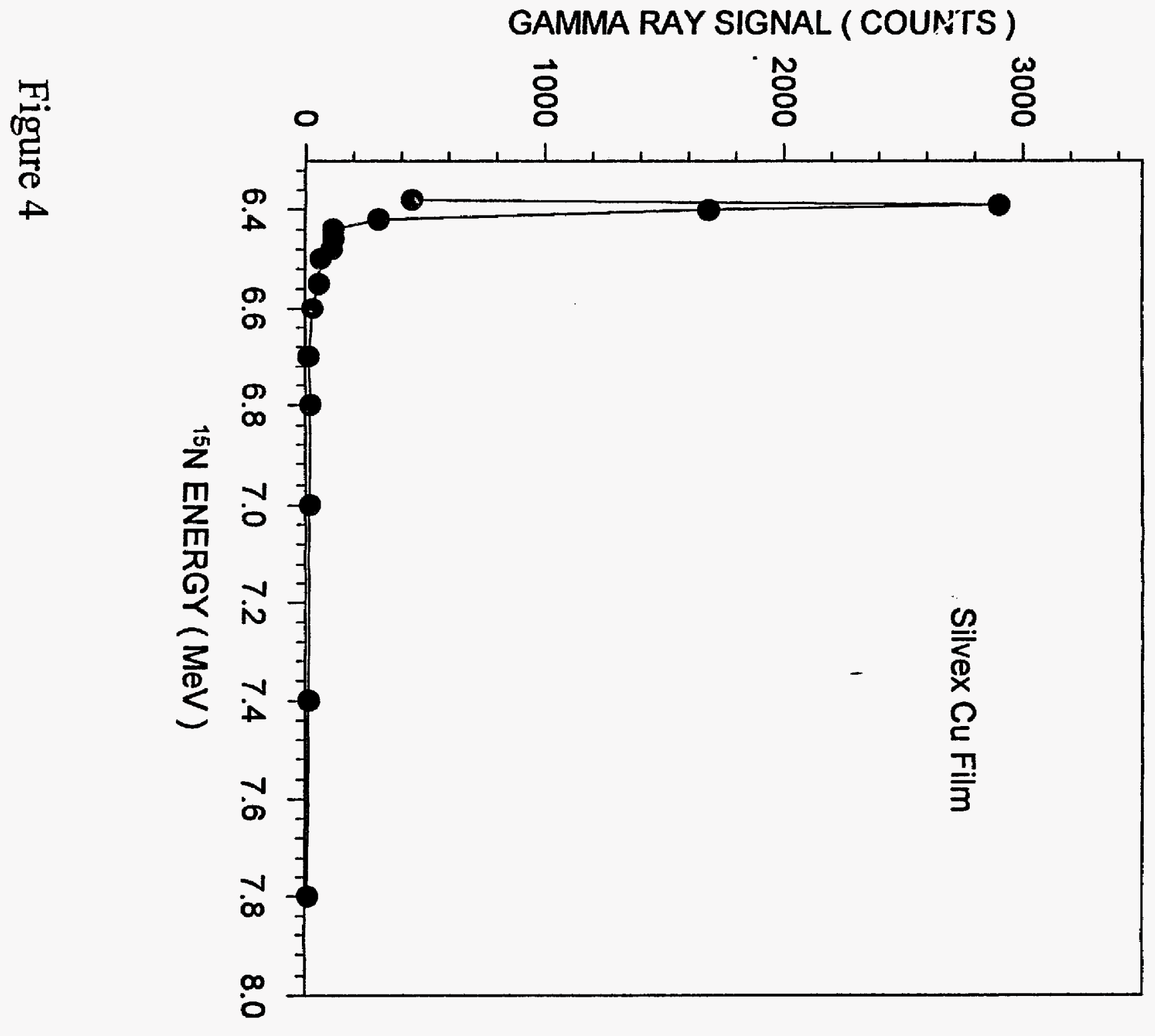




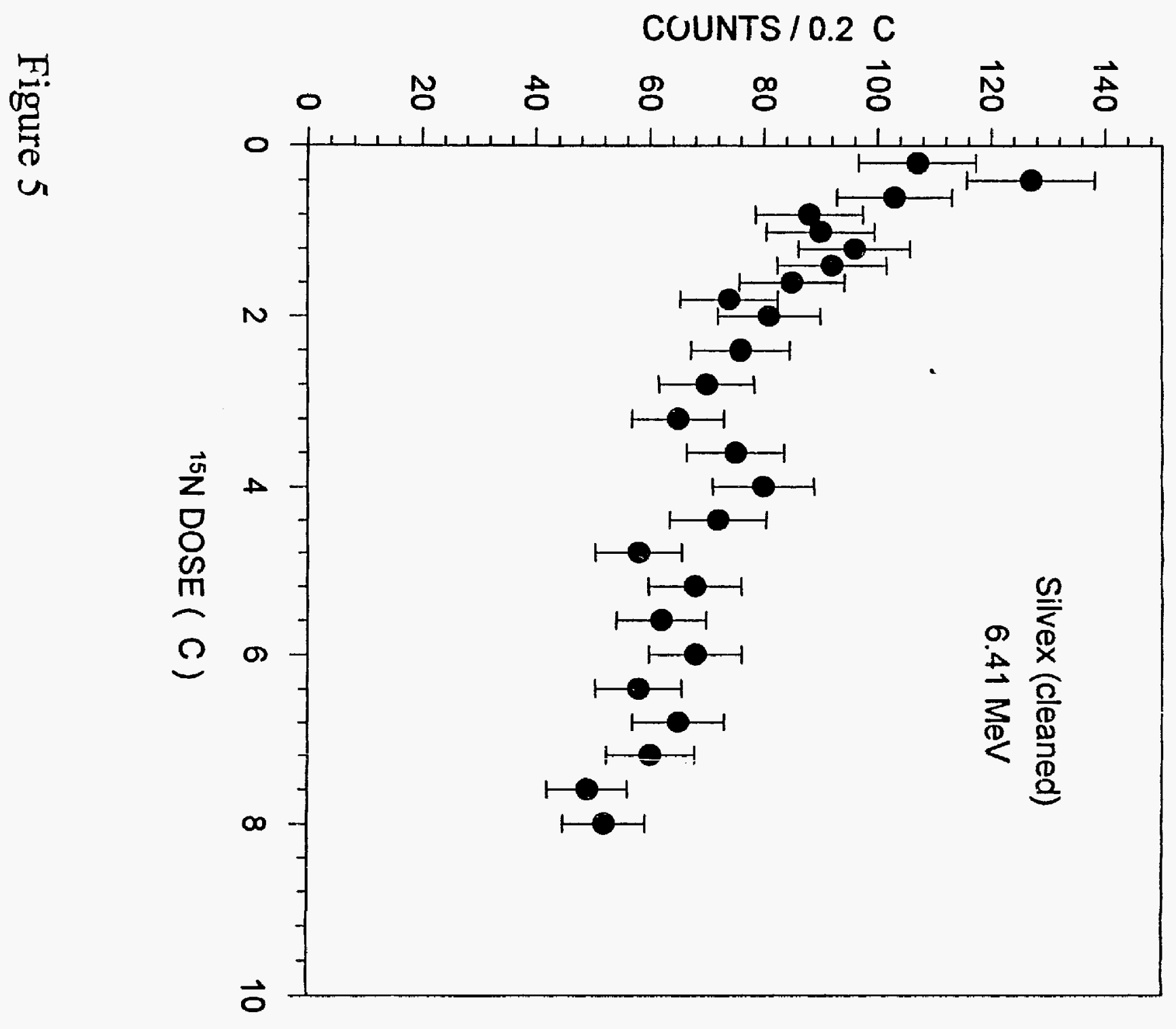


蛋

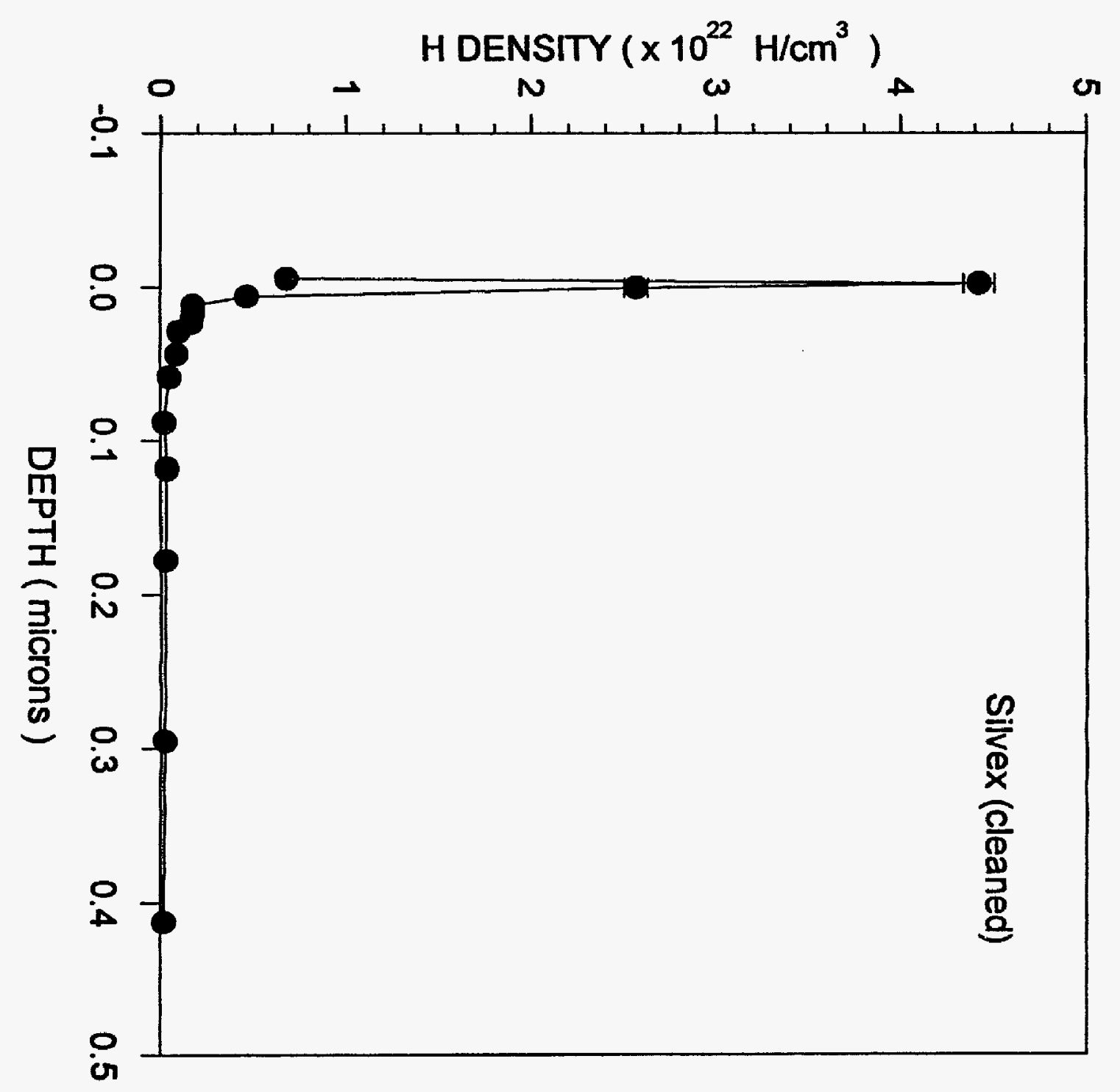




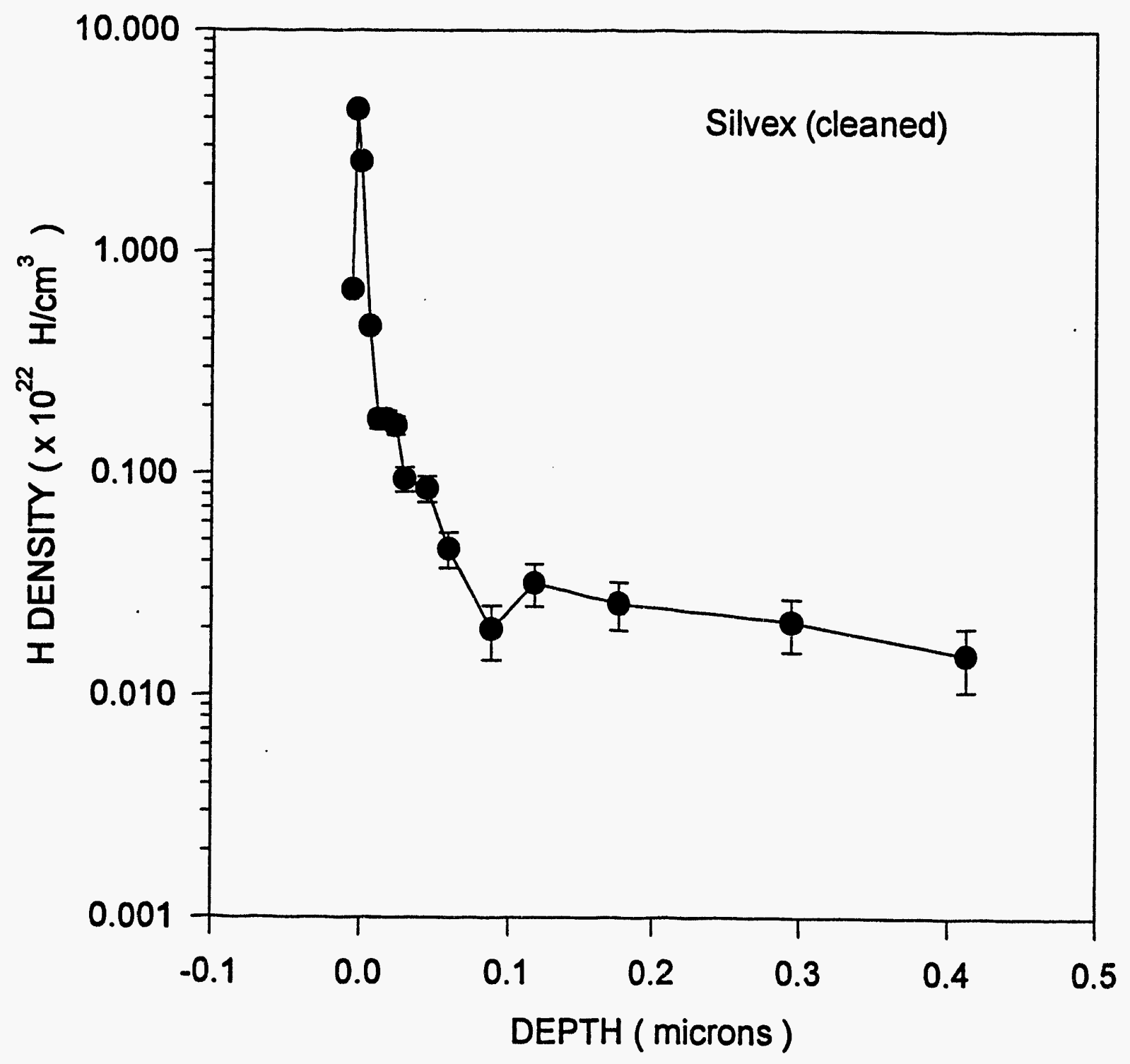

Figure 7 


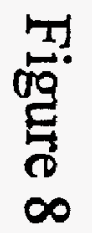

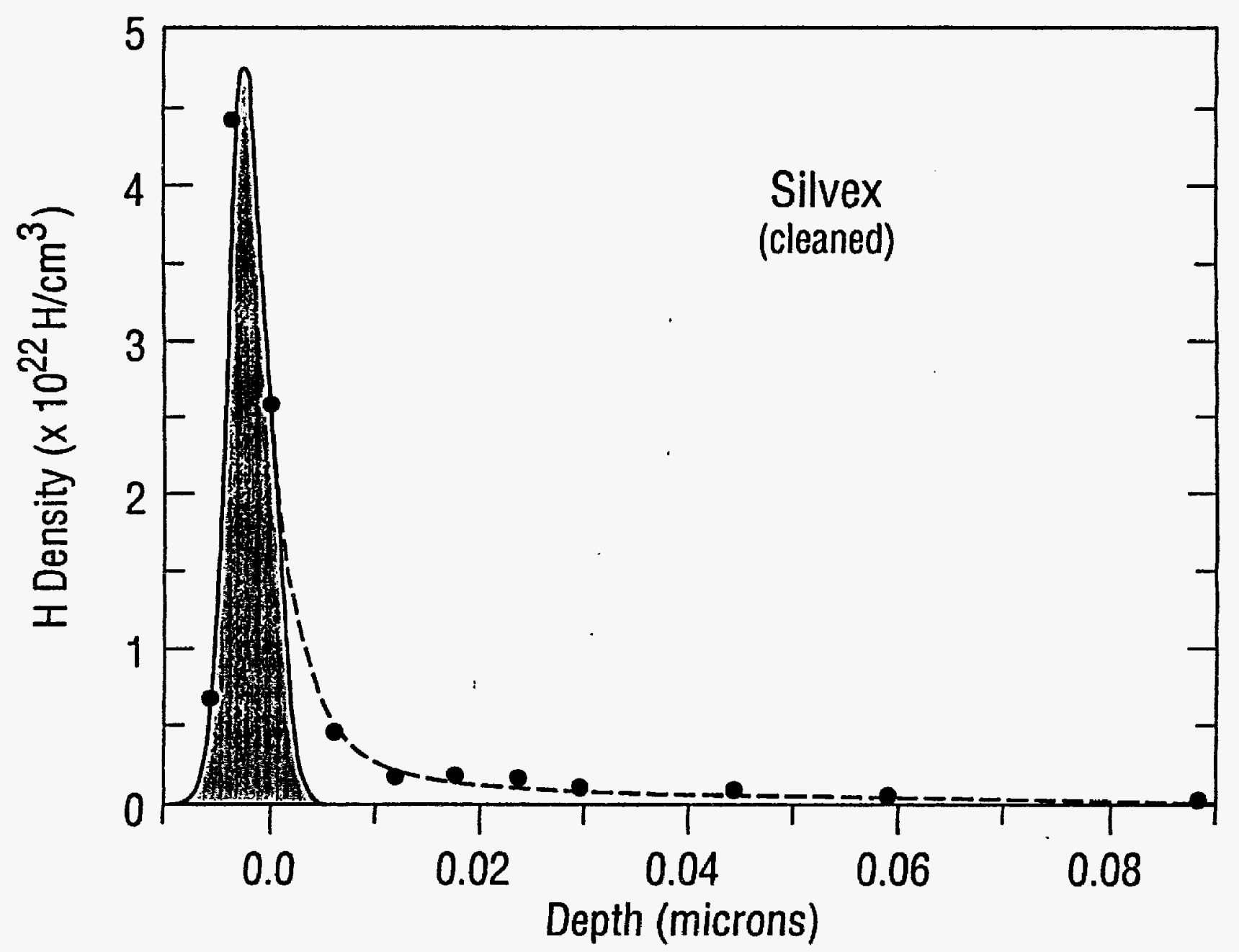




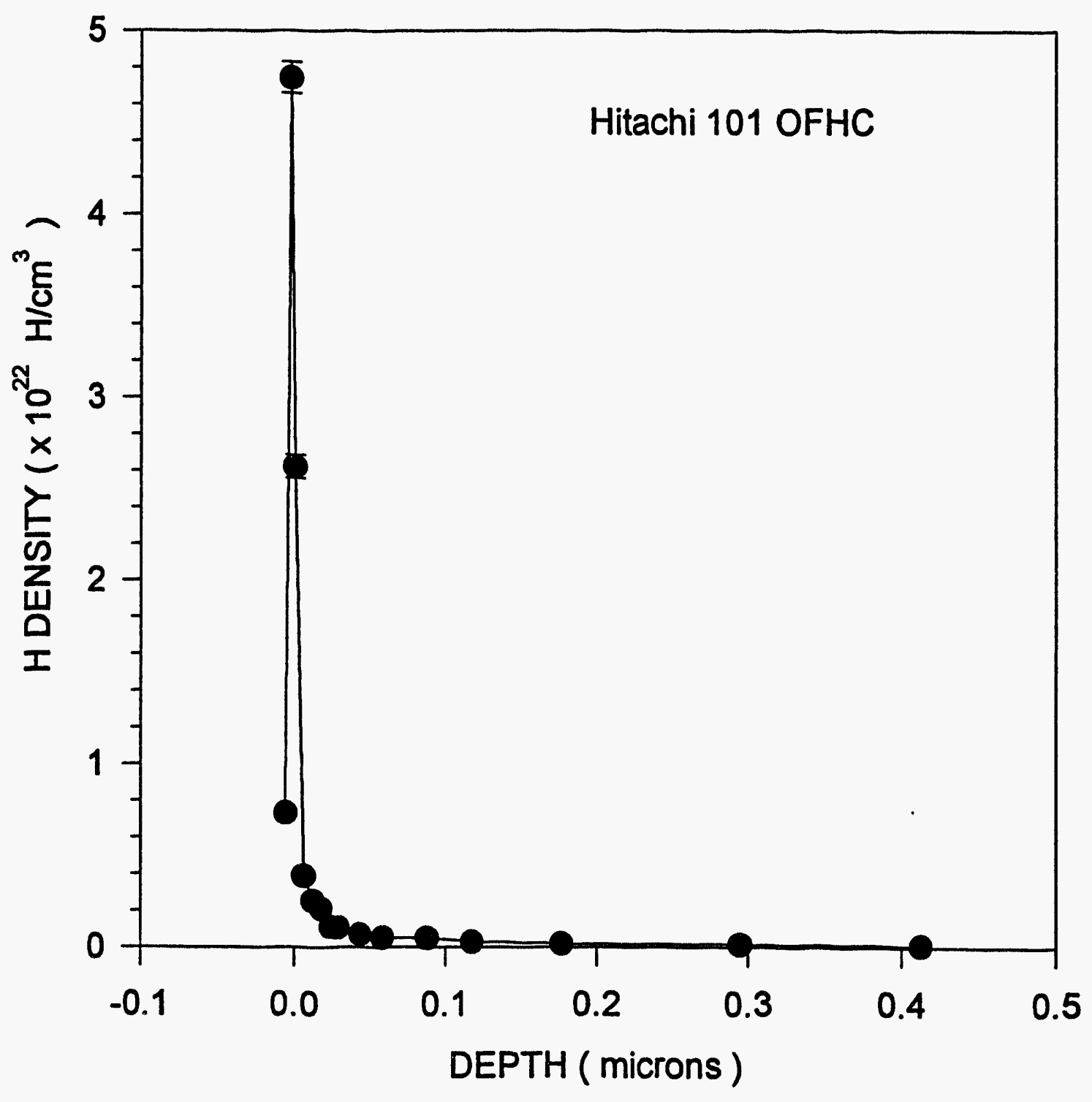

Figure 9 
30
0
0
0
0

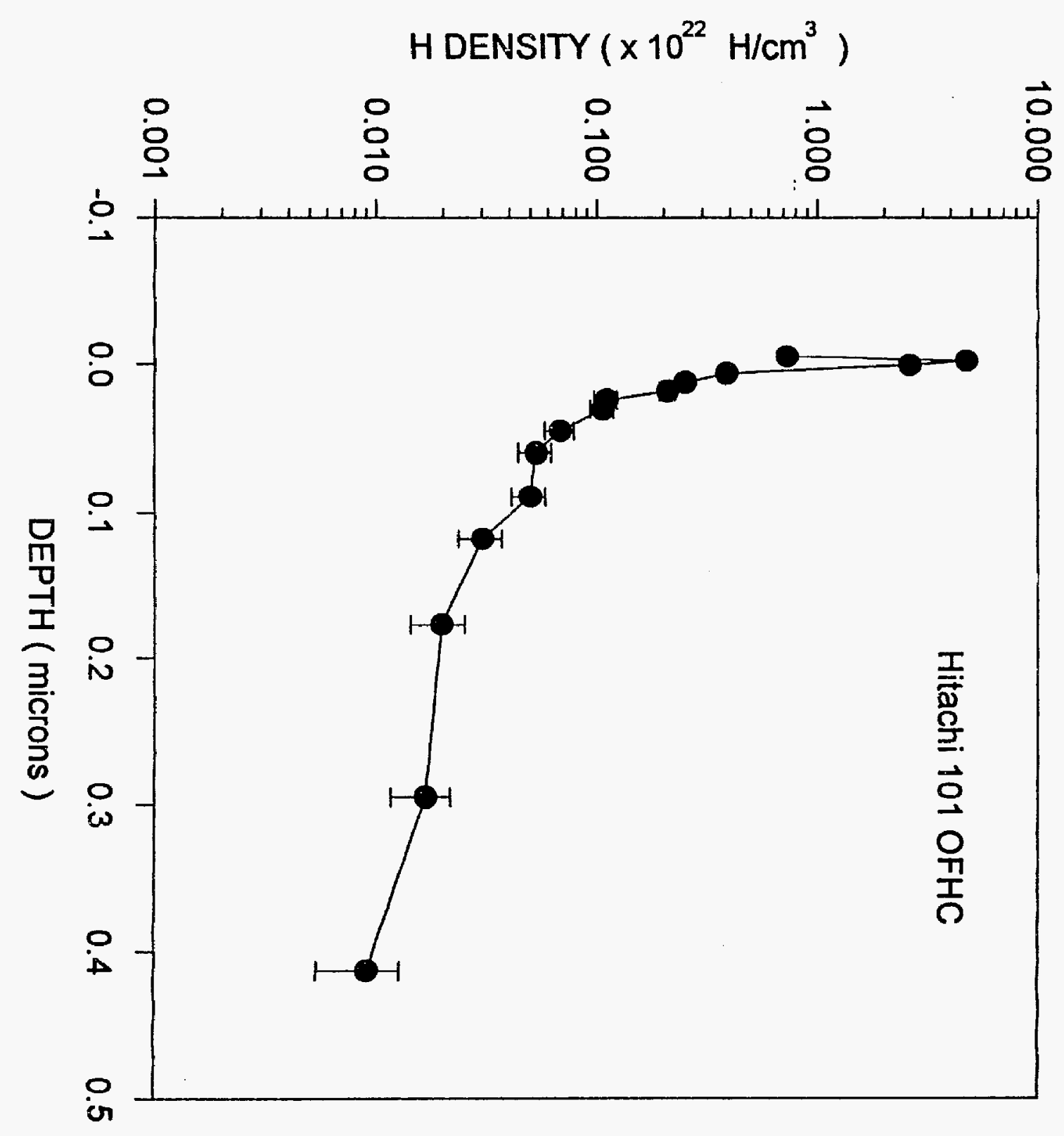




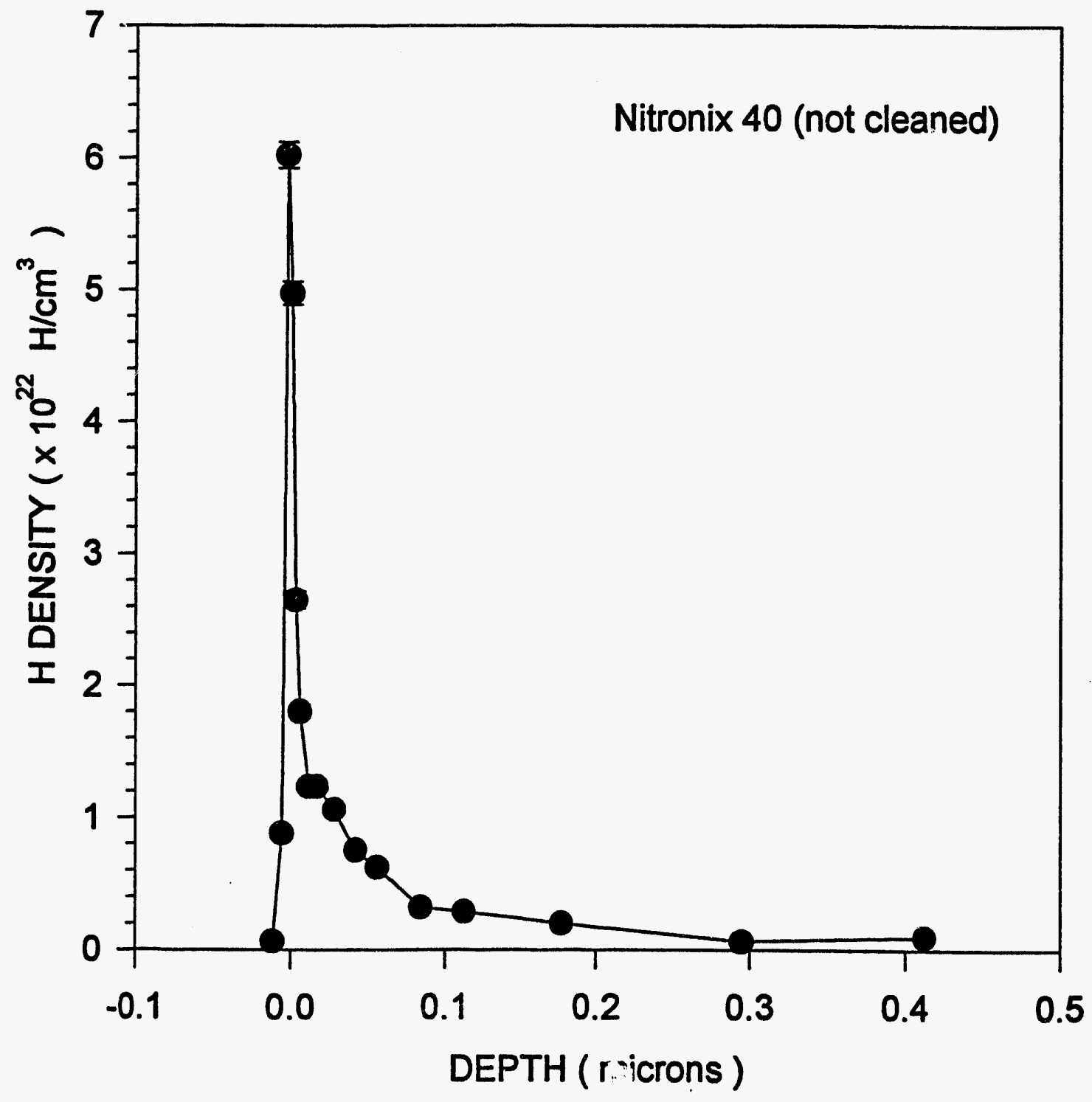

Figure 11 


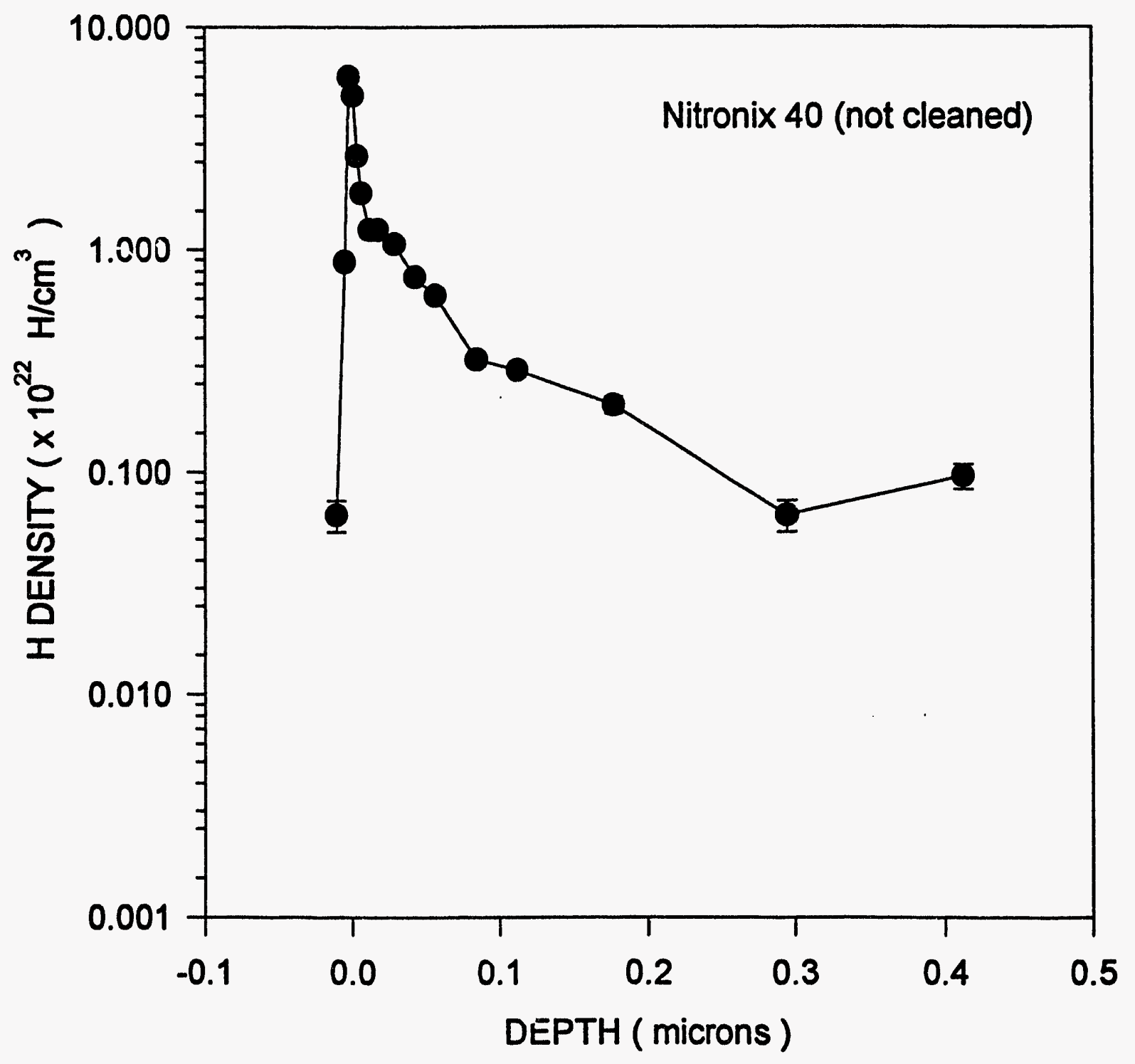

Figure 12 


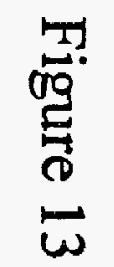

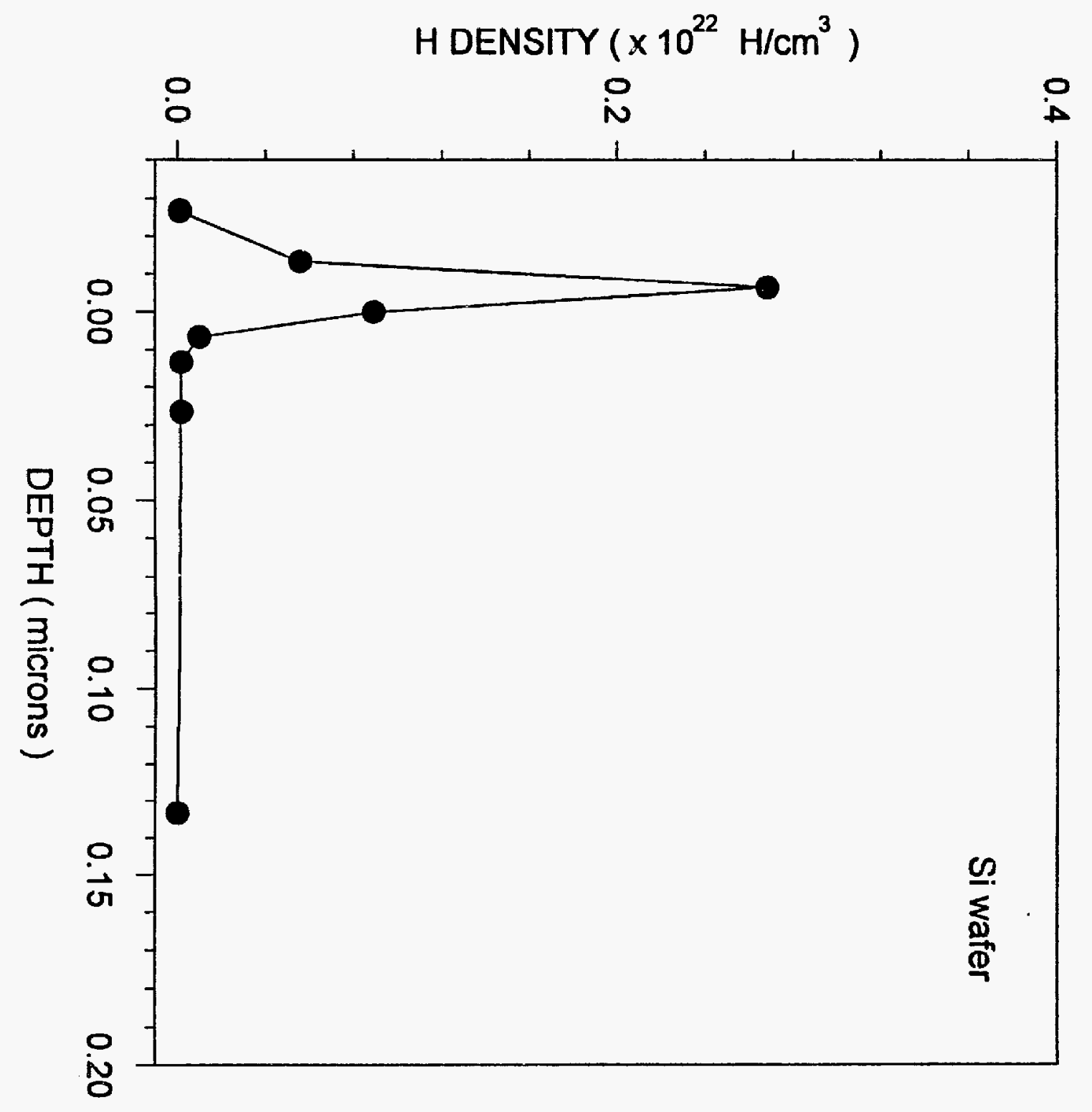




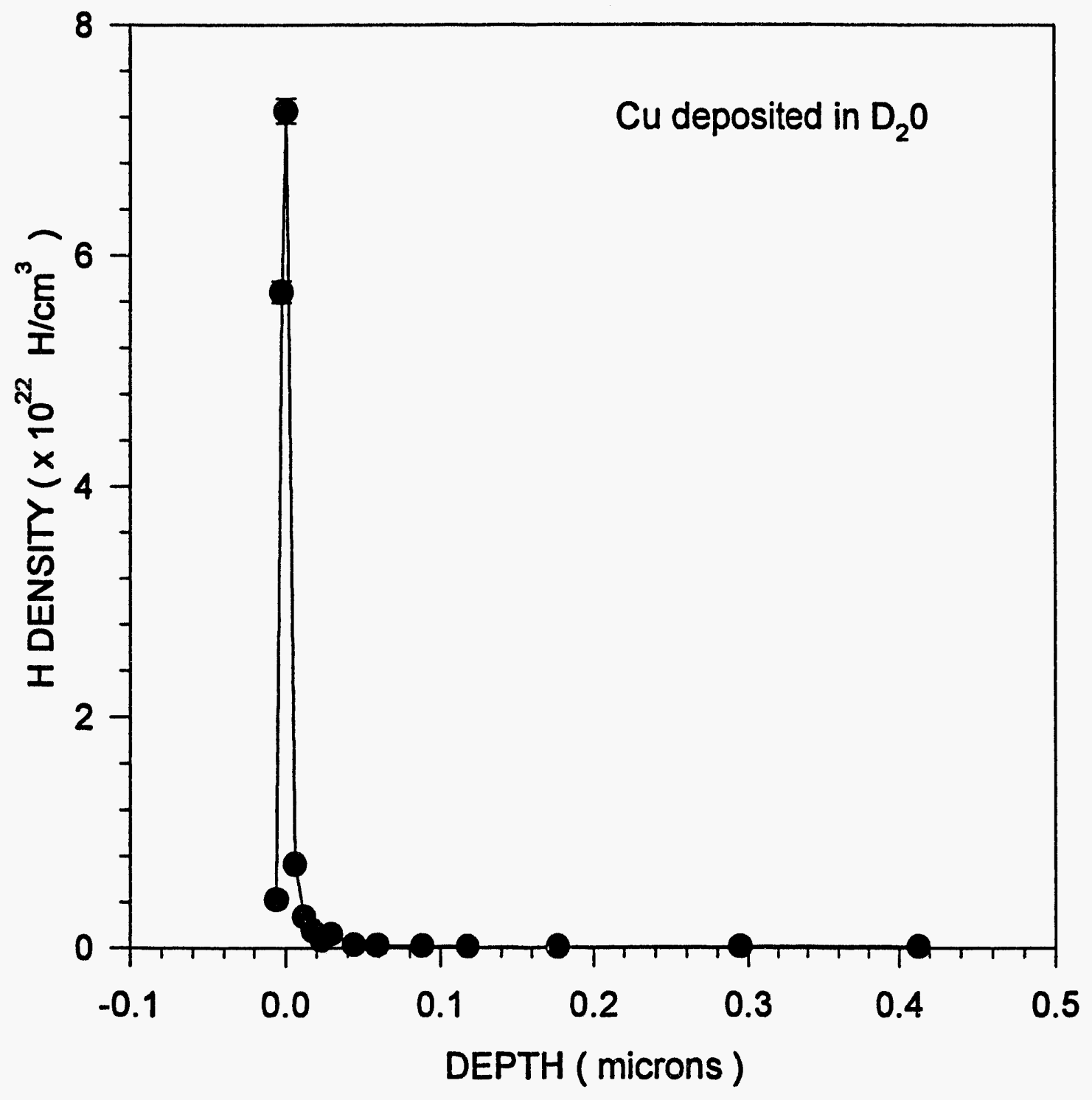

Figure 14 


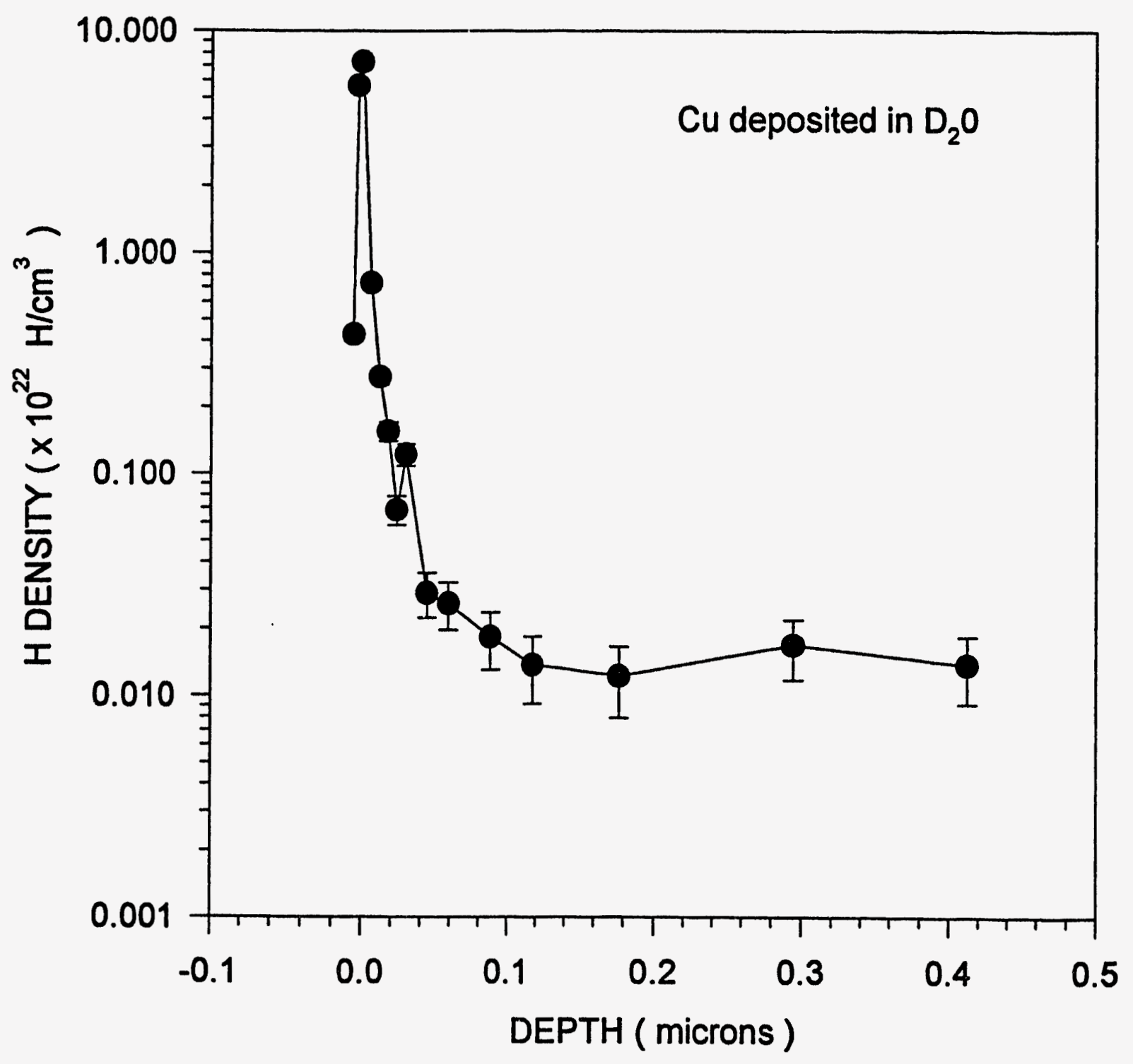

Figure 15 


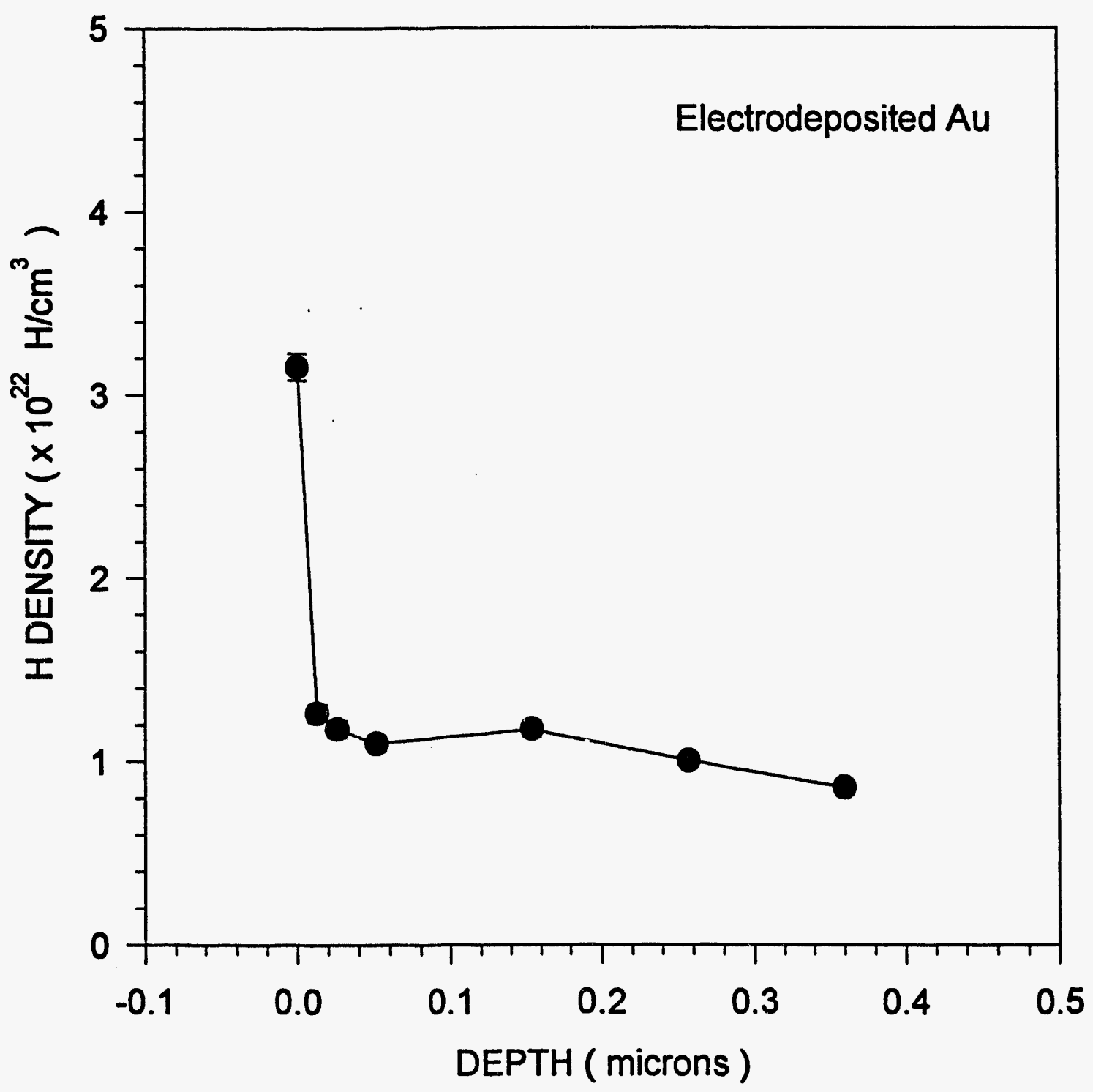

Figure 16 


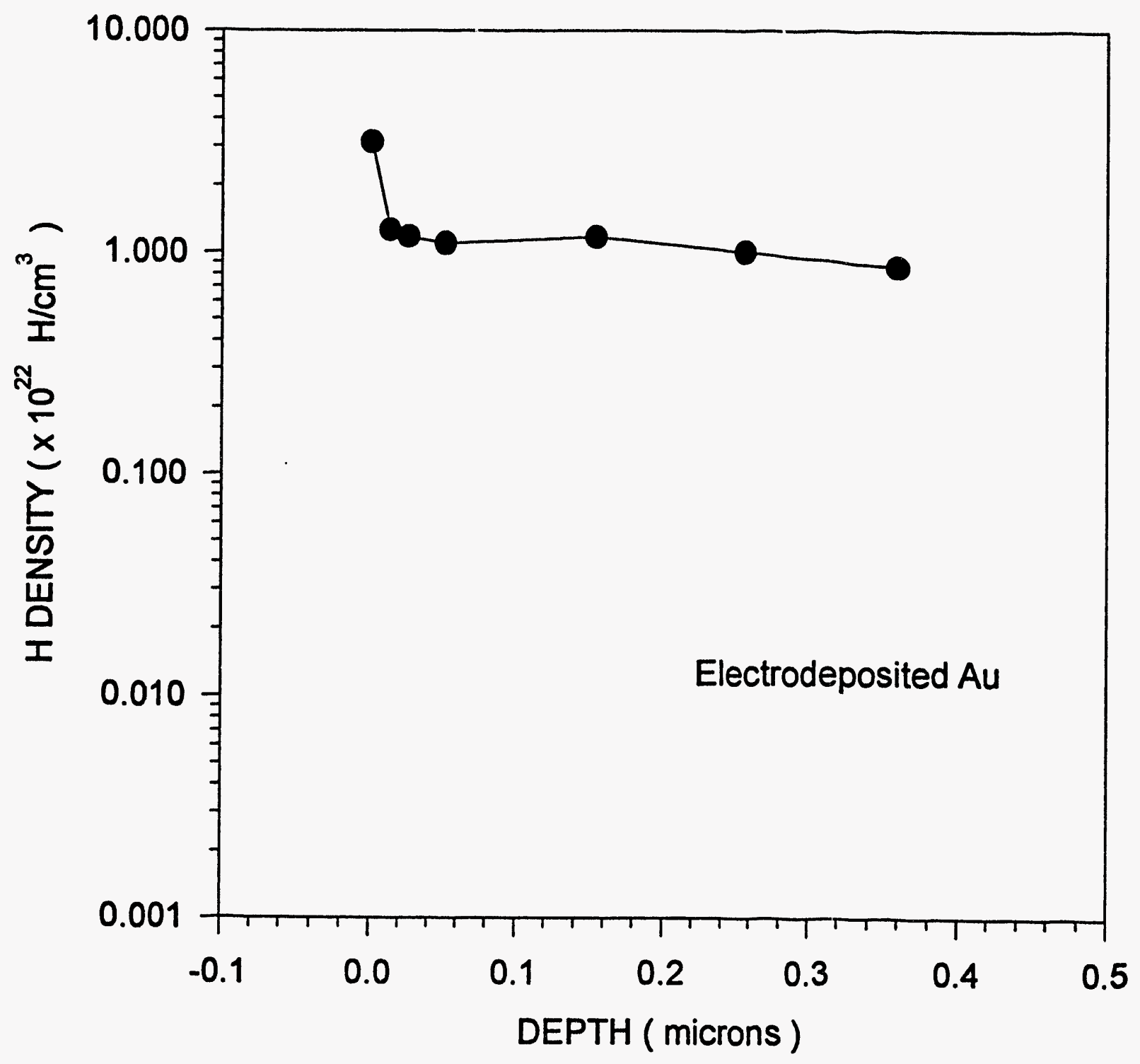

Figure 17 


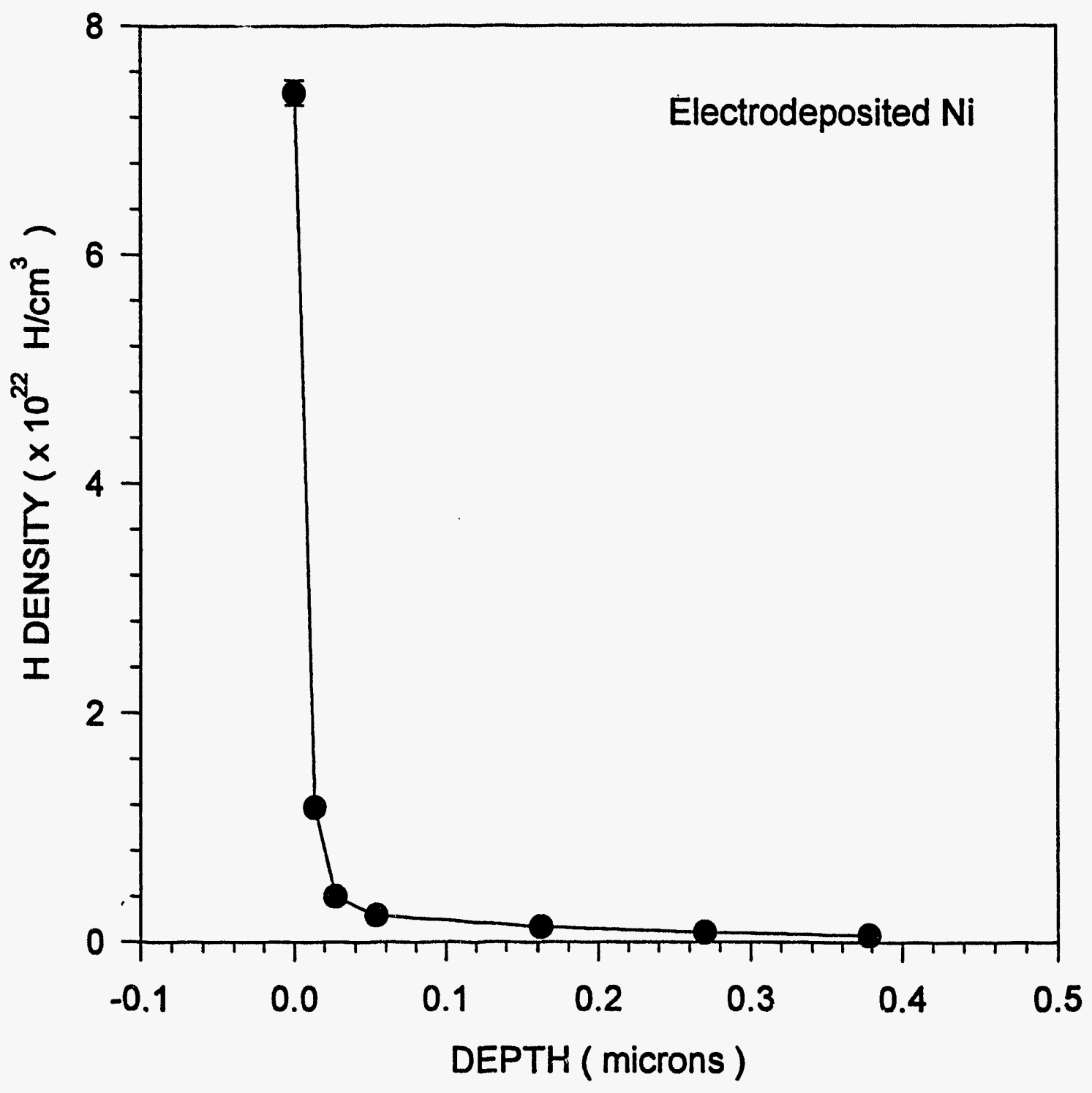

Figure 18 


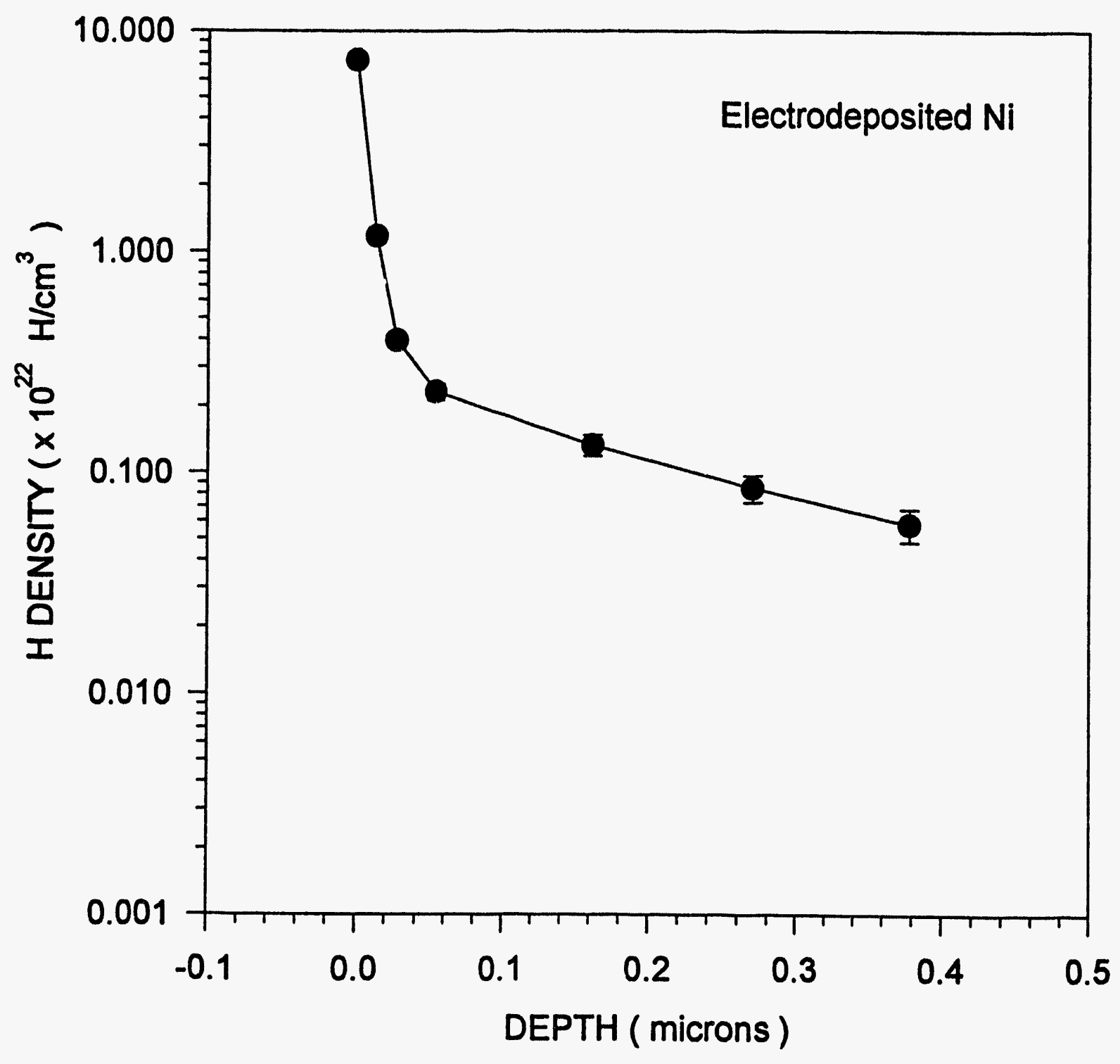

Figure 19 


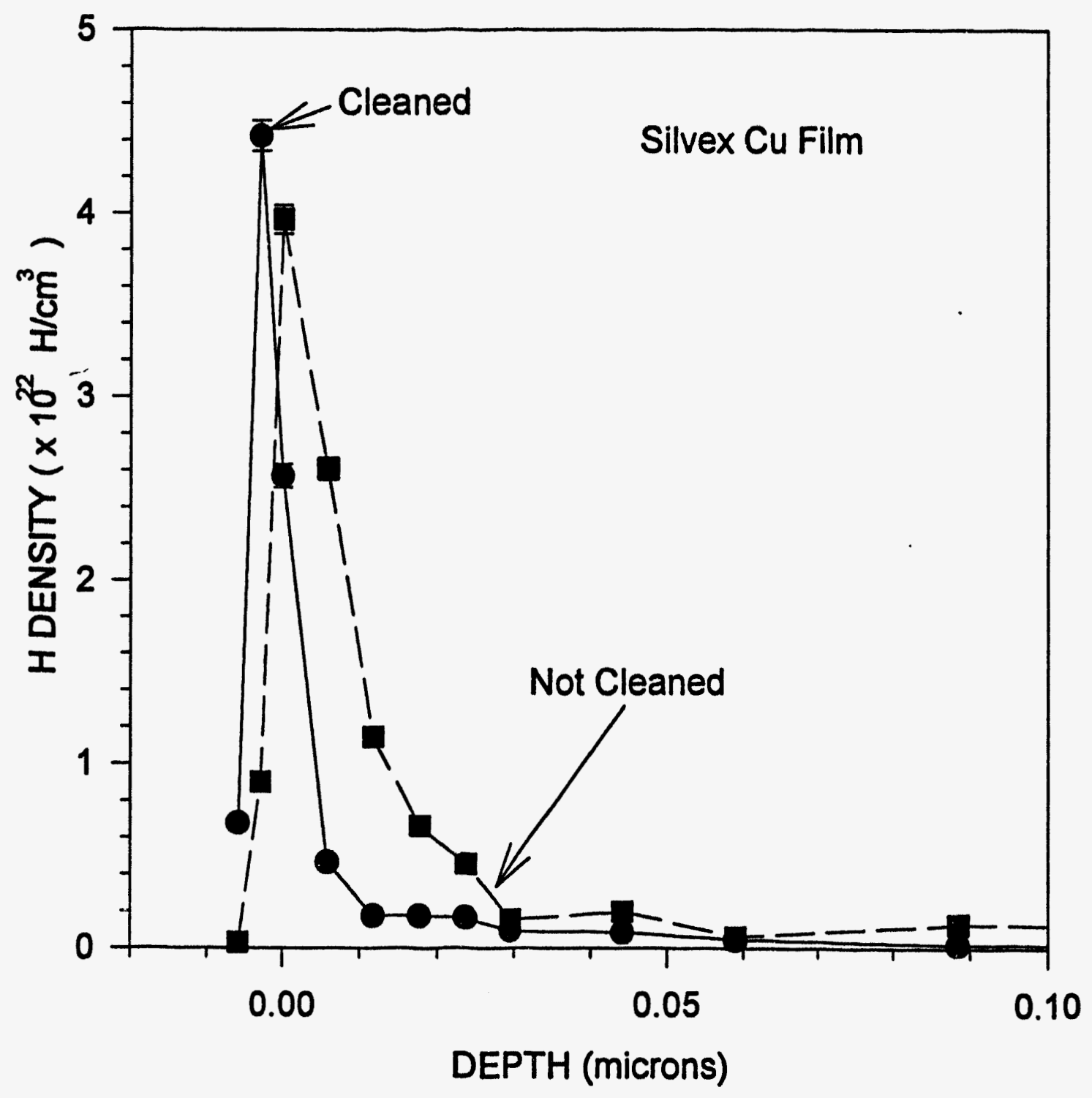

Figure 20 


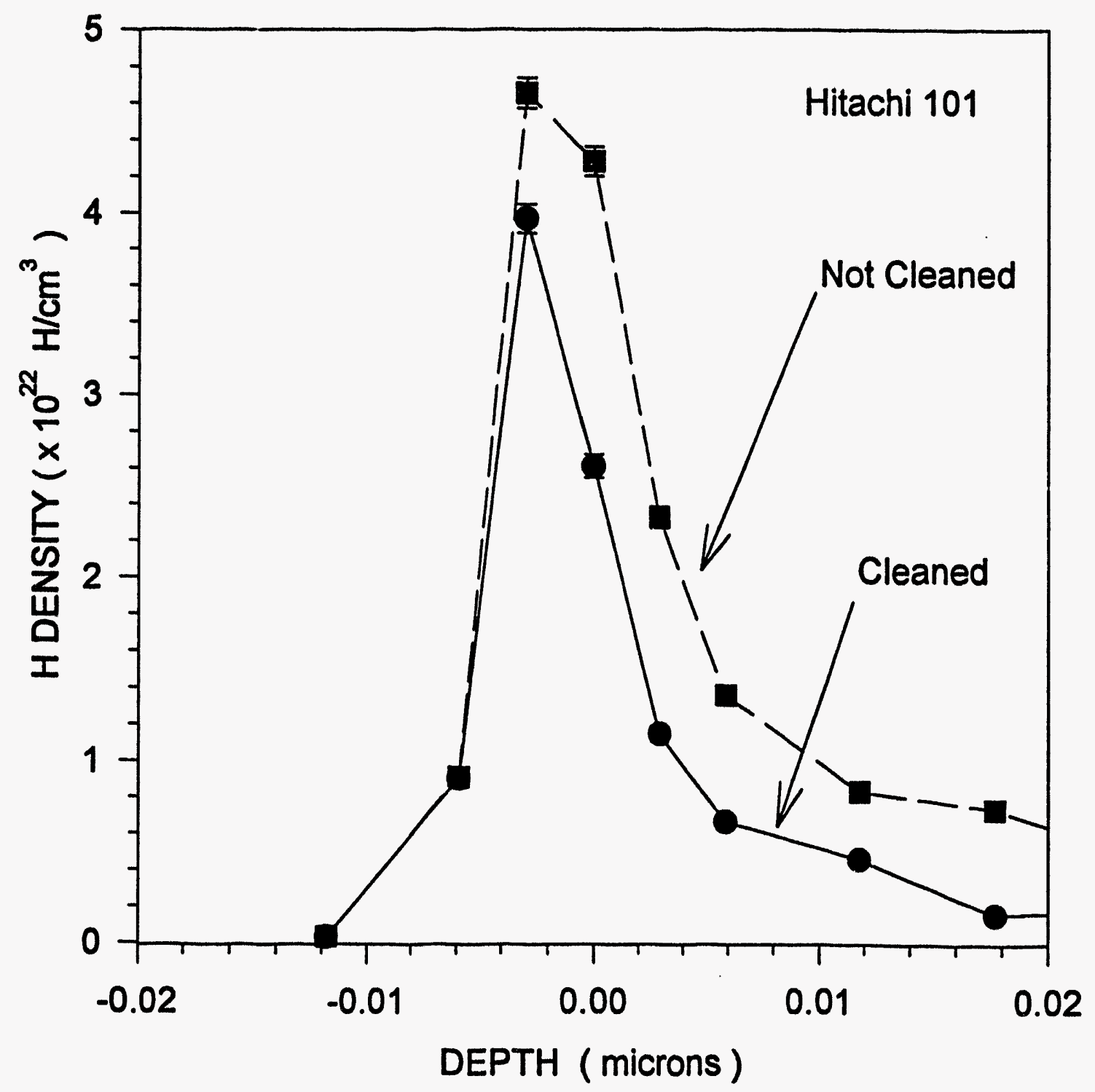

Figure 21 

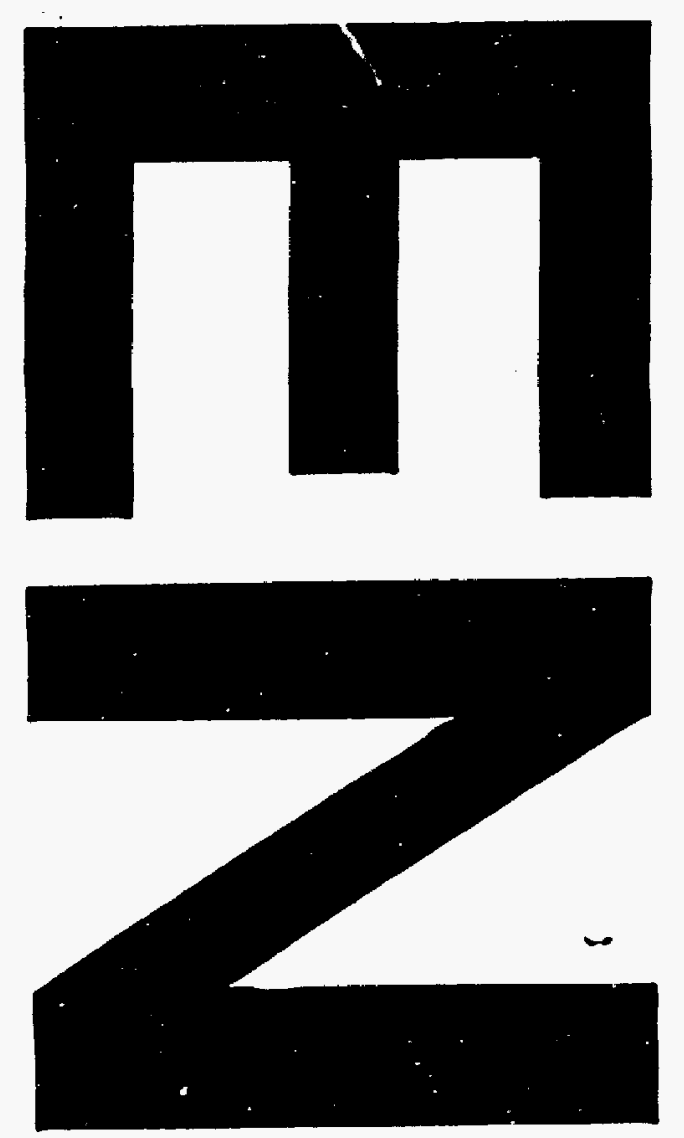

9
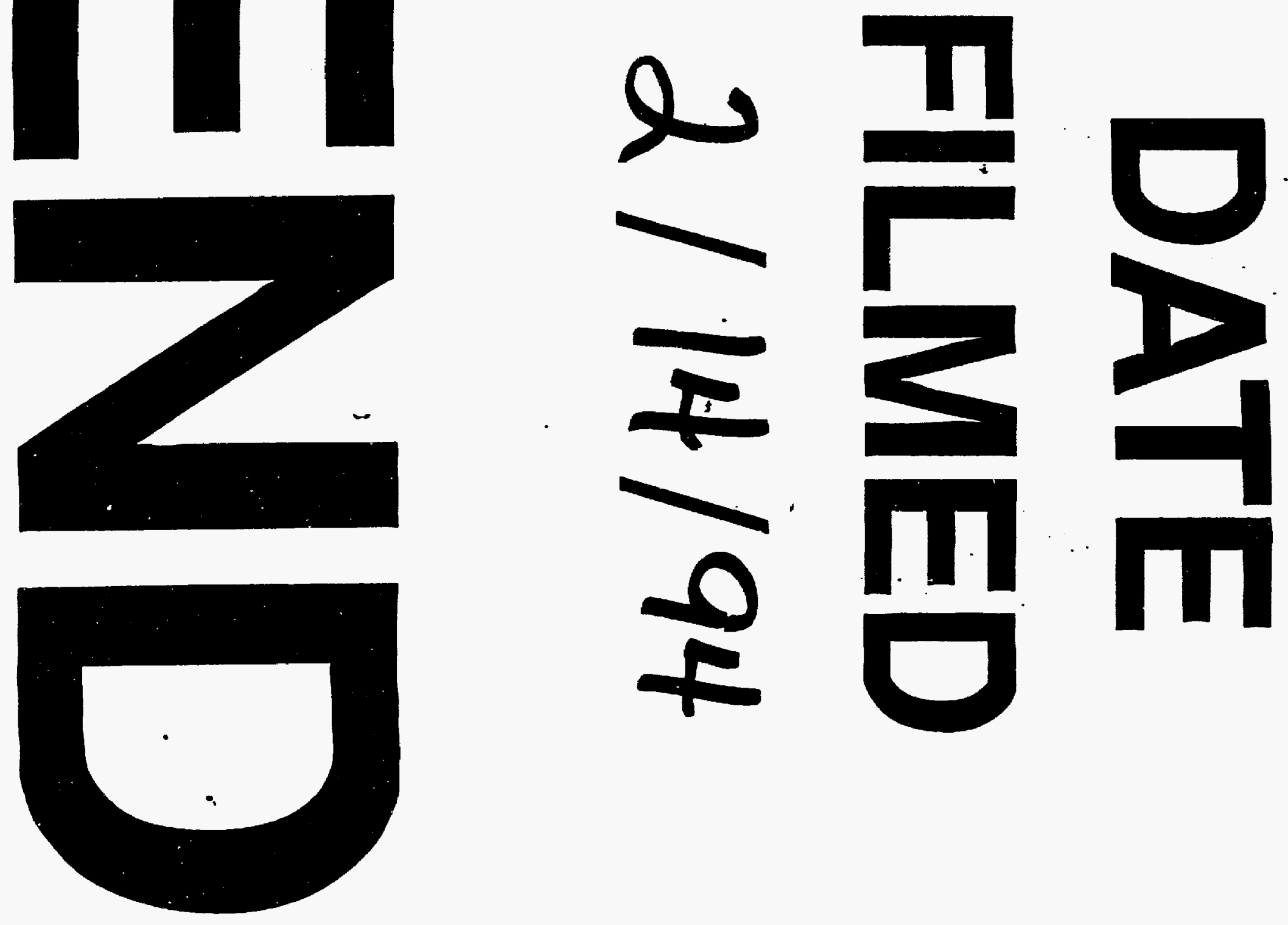
